\title{
Assimilation of surface soil moisture into a multilayer soil model: design and evaluation at local scale
}

\author{
M. Parrens ${ }^{1}$, J.-F. Mahfouf ${ }^{1}$, A. L. Barbu ${ }^{1}$, and J.-C. Calvet $^{1}$ \\ ${ }^{1}$ CNRM-GAME - UMR3589, Météo-France, CNRS, Toulouse, France \\ Correspondence to: J.-C. Calvet (jean-christophe.calvet@meteo.fr)
}

Received: 8 July 2013 - Published in Hydrol. Earth Syst. Sci. Discuss.: 23 July 2013

Revised: 24 December 2013 - Accepted: 10 January 2014 - Published: 19 February 2014

\begin{abstract}
Land surface models (LSM) have improved considerably in the last two decades. In this study, the Interactions between Surface, Biosphere, and Atmosphere (ISBA) LSM soil diffusion scheme is used (with 11 soil layers represented). A simplified extended Kalman filter (SEKF) allows ground observations of surface soil moisture (SSM) to be assimilated in the multilayer LSM in order to constrain deep soil moisture. In parallel, the same simulations are performed using the ISBA LSM with 2 soil layers (a thin surface layer and a bulk reservoir). Simulations are performed over a 3 yr period (2003-2005) for a bare soil field in southwestern France, at the SMOSREX (Surface Monitoring Of the Soil Reservoir Experiment) site. Analyzed soil moisture values correlate better with soil moisture observations when the ISBA LSM soil diffusion scheme is used. The Kalman gain is greater from the surface to $45 \mathrm{~cm}$ than below this limit. For dry periods, corrections introduced by the assimilation scheme mainly affect the first $15 \mathrm{~cm}$ of soil whereas weaker corrections impact the total soil column for wet periods. Such seasonal corrections cannot be described by the two-layer ISBA LSM. Sensitivity studies performed with the multilayer LSM show improved results when SSM $(0-6 \mathrm{~cm})$ is assimilated into the second layer $(1-5 \mathrm{~cm})$ than into the first layer $(0-1 \mathrm{~cm})$. The introduction of vertical correlations in the background error covariance matrix is also encouraging. Using a yearly cumulative distribution function (CDF)matching scheme for bias correction instead of matching over the three years permits the seasonal variability of the soil moisture content to be better transcribed. An assimilation experiment has also been performed by forcing ISBADF (diffusion scheme) with a local forcing, setting precipitation to zero. This experiment shows the benefit of the SSM assimilation for correcting inaccurate atmospheric forcing.
\end{abstract}

\section{Introduction}

It is well known that land surface processes interact strongly with the lower boundary of the atmosphere. In climate and numerical weather prediction (NWP) models, surfaceinteraction processes are represented by land surface models (LSMs). LSMs determine the partitioning of surface energy between sensible and latent heat fluxes, which depend on the quantity of water available in the root zone (Shukla and Mintz, 1982; Koster and Suarez, 1995; Entekhabi et al., 1999). The characterization of soil moisture in deep layers is more important than for surface soil moisture as the superficial reservoir has a small capacity and no memory features. Accurate estimates of root zone soil moisture are also important for many applications in hydrology and agriculture. Therefore, the land dynamics need to be sufficiently accurate. For example, a finer discretization in the vertical soil moisture and temperature profiles allows for a much better description of the nonlinear behavior than two-layer or threelayer models can provide (Reichle, 2000).

Considerable improvements have been made to the initial state of LSMs during the last decade by assimilating remotely sensed near-surface soil moisture data (Houser et al., 1998; Crow and Wood, 2003; Reichle and Koster, 2005; Balsamo et al., 2007). Interest in this was motivated by recent advances in soil moisture remote sensing. Since the 1970s, remote sensing has come to be accepted as a potential tool to access soil moisture at different temporal and spatial scales. Schmugge (1983) shows that the low-frequency microwave range is suitable for measuring the water content of a shallow, near-surface layer. Numerous missions to map surface soil moisture globally have been launched, such as ASCAT (Advanced Scatterometer on board METOP, Wagner et al., 2007), the Advanced Microwave Scanning Radiometer EOS 
(Earth Observation System)(AMSR-E sensor, Njoku et al., 2003), and the Soil Moisture and Ocean Salinity (SMOS) satellite (Kerr et al., 2001), or are scheduled for launch (Soil Moisture Active Passive (SMAP) satellite, Entekhabi et al., 2004). Moreover, the development of soil moisture retrieval algorithms for preexisting microwave remote sensing missions (Wagner et al., 1999; Owe et al., 2001; Bartalis et al., 2007) offers an opportunity to improve the realism of modeled soil moisture. Several authors (Entekhabi et al., 1994, Houser et al., 1998, Walker and Houser, 2001, Ragab, 1995 and Sabater et al., 2007 among others) have shown that combining SSM measured by remote sensing and LSM simulations through a land data assimilation system (LDAS) improves the modeled soil moisture content for deep layers and/or heat fluxes (Pipunic et al., 2013). However, there are considerable uncertainties associated with the use of remotely sensed soil moisture data. In particular, the extent to which the near-surface soil layer represents the underlying soil moisture profile is not well understood.

Satellite data have to be calibrated and validated by observations in situ. The SMOSREX (Surface Monitoring Of the Soil Reservoir Experiment) site located in southwestern France was used for the algorithm validation of SMOS (Saleh et al., 2006, 2007). Over this site, measurements of soil moisture and temperature profiles, meteorological variables and brightness temperatures were obtained for 2003 to 2012 (de Rosnay et al., 2006). Remote sensing and in situ soil measurements are available over fallow and bare soil plots.

A number of studies have been conducted in recent years to investigate the relevance of using variational and Kalman filtering to analyze soil moisture. In 2000, the German Weather Service (Deutscher Wetterdienst) implemented a simplified extended Kalman filter (SEKF) soil moisture analysis using screen-level parameter information (Hess, 2001). Four years later, Balsamo et al. (2004) introduced an online simplified two-dimensional variation (2D-VAR) method instead of a SEKF to retrieve soil moisture. More recently, Météo-France developed an offline SEKF to analyze soil moisture in the SURface EXternalisée (SURFEX) system for research applications (Mahfouf et al., 2009). For the German and French models, the same approach of explicitly computing Jacobians in finite differences based on perturbed simulations is used. In 2010, a new LDAS based on a SEKF was implemented at the European Center for Medium-Range Weather Forecasts (ECMWF) in the global operational Integrated Forecasting System (IFS) (de Rosnay et al., 2013).

In the present work, a SEKF is used to assimilate in situ observations, gathered at SMOSREX over bare soil, into the Interactions between Surface, Biosphere, and Atmosphere (ISBA) LSM. Only the surface soil moisture (SSM) measured from the surface to $6 \mathrm{~cm}$ depth at 06:00LST (Local Standard Time) is assimilated in the LDAS, if the observation is available. This experimental setup is used to represent the daily assimilation of remote sensing data at dawn. For example, SMOS has an ascending Equator crossing time at 06:00 LST. Two versions of ISBA are used: the original force restore scheme (Noilhan and Mahfouf, 1996) and a more complex diffusion scheme using the Richards equation (Decharme et al., 2011). Hereafter, the two ISBA versions are referred to as ISBA-2L and ISBA-DF, respectively. The implementation of SEKF within ISBA-2L has been investigated by several authors, such as Draper et al. (2011), Barbu et al. (2011) and Albergel et al. (2010). In these studies, a twoor three-soil-layer configuration was used. Unlike ISBA-2L, ISBA-DF (diffusion version) allows a fine discretization of the soil to be used (11 soil layers are considered). In this study, a first attempt is made to use the ISBA-DF in a data assimilation experiment. This work focuses on a bare soil site in order to isolate the thermal and water transfers in the soil without any interference from processes related to the vegetation, such as transpiration. Decharme et al. (2011) had already studied differences between ISBA-2L and ISBA-DF using SMOSREX data over the fallow site. The behavior of these two LSMs over bare soil has not yet been compared. The period under investigation extends over three contrasted years from 2003 to 2005, including the 2003 drought. In addition, the role of bias correction in the assimilation is discussed regarding the mass balance in the root zone. Despite the lack of a root zone in the bare soil, this term will be used below to represent the total active soil depth.

The main objectives of this study are (1) to compare the soil moisture simulations from ISBA-2L and ISBA-DF over the bare soil, (2) to evaluate the role of the assimilation of ground observations of SSM for these two LSMs and (3) to investigate different configurations of ISBA-DF LDAS in four sensitivity cases. The SMOSREX data, ISBA-2L and ISBA-DF LSM and the SEKF algorithm are presented in Sect. 2. Assimilation results and sensitivity studies are presented in Sect. 3 and discussed in Sect. 4. Section 5 summarizes the main conclusions of the study.

\section{Material and methods}

\subsection{The SMOSREX site and the soil moisture time series}

The SMOSREX long-term experiment (2001-2012) was aimed at improving the modeling of land surface processes in the context of the SMOS mission (de Rosnay, 2006). The SMOSREX site is located in southwestern France $\left(43^{\circ} 23^{\prime} \mathrm{N}\right.$, $1^{\circ} 17^{\prime} \mathrm{E}$, at $188 \mathrm{~m}$ altitude) and is divided into two parts: a bare soil plot and a fallow plot. Soil moisture was measured at depths of $0-0.06,0.10,0.20,0.30,0.40,0.50,0.60,0.70$, 0.80 and $0.90 \mathrm{~m}$ every half hour. Soil probes were calibrated from gravimetric measurements (Schmugge et al., 1980). A weather station measured precipitation, $2 \mathrm{~m}$ air temperature and air humidity, $10 \mathrm{~m}$ wind speed, atmospheric pressure, and incoming solar and atmospheric radiation every $30 \mathrm{~min}$. An L-band radiometer called LEWIS (Lemaître et al., 2004) 
measuring brightness temperature at two polarizations and five different angles is also present at the SMOSREX site. In this study, we focus on the bare soil plot. The percentage of sand and clay observed from 0.1 to $0.90 \mathrm{~m}$ depth for bare soil on the SMOSREX site is displayed in Fig. 1a.

Only the years 2003, 2004 and 2005 were considered because, for the bare soil plot, the soil moisture data at depths ranging from 0.20 to $0.90 \mathrm{~m}$ are missing from 2006 onwards. The surface soil moisture (SSM) measurements, i.e., from the surface to $6 \mathrm{~cm}$, were used for assimilation and measurements from 10 to $95 \mathrm{~cm}$ were used for validation purposes. In order to avoid frozen soil conditions, SSM observations made when the surface temperature was below a threshold of $4{ }^{\circ} \mathrm{C}$ were discarded

\subsection{Land surface models}

The ISBA land surface model (Noilhan and Planton, 1989; Noilhan and Mahfouf, 1996) describes the surface processes in weather and climate applications. This model shows the evolution of land surface state variables (surface and soil temperatures, surface and root zone soil moisture content) and the exchanges of heat and water between the low level atmosphere, the vegetation and the soil. In this study, the SURFEX (SURFace EXternalisée) modeling platform (Masson et al., 2013) version 7.2 containing the ISBA LSM was used. SURFEX is designed for research and operational applications and includes several options of ISBA. In this study, SURFEX is forced by local atmospheric observations and runs without feedback between the surface and the atmosphere (i.e., SURFEX is used offline). Moreover, to match measurement levels, the total soil depth was set to $0.95 \mathrm{~m}$. The two options of the ISBA LSM (ISBA-2L and ISBA-DF) used in this study are summarized below.

\subsubsection{ISBA-2L}

The ISBA-2L version of SURFEX is based on the force restore approach, according to Deardorff (1977). This LSM is used in the operational NWP models at Météo-France. The soil is composed of two layers, the first layer being represented by a skin soil top layer $1 \mathrm{~cm}$ thick and the second by a bulk reservoir. The first layer is used to compute the SSM and soil evaporation while the second layer is used to compute the total soil moisture and contributes to the evapotranspiration (Boone et al., 1999). Mahfouf and Noilhan (1996) introduced a representation of gravitational drainage. In the force restore equations, the soil moisture dynamics depend on several thresholds - saturation $\left(w_{\text {sat }}\right)$, wilting point $\left(w_{\text {wilt }}\right)$, and field capacity $\left(w_{\mathrm{fc}}\right)$. These parameters are related to the soil textural properties (Mahfouf and Noilhan, 1996). In this work, $w_{\mathrm{fc}}$ and $w_{\text {wilt }}$ were derived from the clay content observations and set to 0.30 and $0.17 \mathrm{~m}^{3} \mathrm{~m}^{-3}$, respectively. $w_{\text {sat }}$ was derived from the sand content observations and set to $0.45 \mathrm{~m}^{3} \mathrm{~m}^{-3}$. The modeled surface soil moisture and root
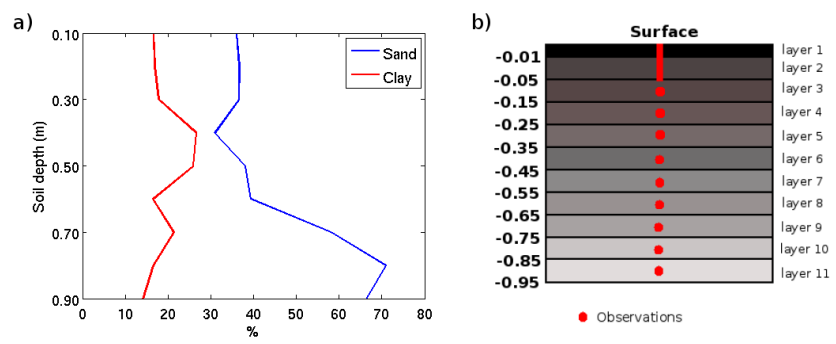

Fig. 1. (a) Sand and clay soil profile (in \%) measured at the SMOSREX bare soil site. (b) Soil profile model used with ISBADF. The depth of each layer is given in meters. Red dots are places where soil moisture observations were made.

zone soil moisture are referred to hereafter as $w_{1}$ and $w_{\text {tot }}$, respectively.

\subsubsection{ISBA-DF}

The ISBA-DF LSM is a new ISBA version including a soil multilayer diffusion scheme (Decharme et al., 2011), which explicitly solves mass and heat-diffusive equations. The ISBA-DF soil hydrology uses the "mixed" form of the Richards equation to describe the water mass transfer within the soil via Darcy's law. Moisture and temperature profiles can be computed according to the vertical soil texture properties. Computations are performed using the SMOSREX soil texture displayed in Fig. 1a. In ISBA-DF, unlike in ISBA-2L, the soil moisture dynamics do not depend on the specification of a volumetric field capacity. In this study, 11 soil layers were considered, corresponding to the locations of observation instruments at the SMOSREX site. Figure $1 \mathrm{~b}$ shows the soil discretization used in the ISBA-DF LSM and the placement of each probe. The node of each ISBA-DF soil layer corresponds to the depth of each probe: $0.10,0.20,0.30,0.40$, $0.50,0.60,0.70,0.80$ and $0.90 \mathrm{~m}$. Close to the surface, two layers were considered: $0-0.01$ and $0.01-0.05 \mathrm{~m}$. Hereafter, soil moisture in the $n$th layer is denoted by $w_{n}$ and the total soil water $w_{\text {tot }}$ is the weighted average of $w_{n}$.

\subsection{The simplified extended Kalman filter}

In this section, the classical notations of data assimilation proposed by Ide et al. (1997) are used. The equation for the $i$ th model state forecast and update at time step $t_{i}$ is

$\boldsymbol{x}^{\mathrm{b}}\left(t_{i}\right)=\mathcal{M}_{i-1}\left[\boldsymbol{x}^{\mathrm{a}}\left(t_{i-1}\right)\right]$.

The equation for the $i$ th state analysis, occurring at time $t_{i}$ is

$\boldsymbol{x}^{\mathrm{a}}\left(t_{i}\right)=\boldsymbol{x}^{\mathrm{b}}\left(t_{i}\right)+\mathbf{K}_{i}\left(\boldsymbol{y}_{i}^{\mathrm{o}}-\mathcal{H}_{i}\left[\boldsymbol{x}^{\mathrm{b}}\left(t_{i}\right)\right]\right)$

where $\boldsymbol{x}$ indicates the model state and $\boldsymbol{y}^{0}$ is the observation vector. The superscripts $a, b$ and o indicate the analysis, the background and the observations, respectively. Analysis increments are the difference between the analysis and the 
background. $\mathcal{M}$ is the nonlinear forecast model and $\mathcal{H}$ is the nonlinear observation operator. Both in ISBA-2L and ISBA$\mathrm{DF}$, the observation vector is $\boldsymbol{y}^{0}=(\mathrm{SSM})$. The model state vector is different following the LSM used:

$\boldsymbol{x}_{\text {ISBA-2L }}=\left[w_{1}, w_{\text {tot }}\right]$

$\boldsymbol{x}_{\mathrm{ISBA}-\mathrm{DF}}=\left[w_{1}, w_{2}, w_{3}, w_{4}, w_{5}, w_{6}, w_{7}, w_{8}, w_{9}, w_{10}, w_{11}\right]$.

The observations occurred $24 \mathrm{~h}$ after the analysis time and $\mathcal{H}$ includes a $24 \mathrm{~h}$ integration of the forecast model (Draper et al., 2011). The available observations are assimilated at 06:00 LST. The Kalman gain is given by

$\mathbf{K}_{i}=\mathbf{B}_{i} \mathbf{H}_{i}^{\mathrm{T}}\left(\mathbf{H}_{i} \mathbf{B}_{i} \mathbf{H}_{i}^{\mathrm{T}}+\mathbf{R}_{i}\right)^{-1}$

where the Jacobian matrix $\mathbf{H}$ is the linearization of $\mathcal{H}$ and $\mathbf{H}^{\mathrm{T}}$ its transpose. $\mathbf{H}$ is obtained using a finite difference approach, individually perturbing each component $x_{j}$ of the initial model state $\boldsymbol{x}$ at time $t_{0}$ by a small amount $\delta x_{j}$. The Jacobian is expressed as the difference of the prognostic states between perturbed and reference runs at the end of the assimilation interval at time $t_{i}$, divided by the initial perturbation:

$\mathbf{H}=\frac{\mathcal{H}\left(\boldsymbol{x}+\delta x_{j}\right)-\mathcal{H}(\boldsymbol{x})}{\delta x_{j}}$.

For all the experiments, the perturbation size is set to $0.001 \mathrm{~m}^{3} \mathrm{~m}^{-3}$. Mahfouf et al. (2009) have shown that these very small perturbations lead to good approximations of the linear behavior of the observation operator. The Jacobian values are computed with a daily time step $\left(t_{i}-t_{0}=24 \mathrm{~h}\right)$. The examination of the Jacobian matrices is important for understanding the data assimilation performance. $\mathbf{B}$ and $\mathbf{R}$ are the covariance matrices of the background and observations errors, respectively. The SEKF does not cause B to evolve through a forecast cycle, unlike the traditional EKF. Draper et al. (2009) found that, for assimilating near-surface soil moisture into ISBA LSM, the analyzed soil moisture generated by the EKF and the SEKF were not substantially different. This result is explained by the fact that the increase in the background error during each forward propagation step is balanced by the decrease in the error during the analysis step and the difficulties of specifying the $\mathbf{Q}$ matrix (model error). Moreover, Sabater et al. (2007) suggested that, at the SMOSREX location, a fixed background error was more accurate and stable than an evolving background error.

The performance of an analysis scheme depends on the use of appropriate statistics for background and observation errors. For all the experiments, the observation standard deviation error for SSM was set to $0.02 \mathrm{~m}^{3} \mathrm{~m}^{-3}$. This error is consistent with that chosen by Sabater et al. (2007) at the SMOSREX site.

In the ISBA-2L assimilation experiment, $\mathbf{B}$ was a diagonal matrix with the standard deviation errors $\sigma_{w_{1}}$ and $\sigma_{w_{\text {tot }}}$ set to 0.02 and $0.005 \mathrm{~m}^{3} \mathrm{~m}^{-3}$, respectively. The ratio between $\sigma_{w_{1}}$ and $\sigma_{w_{\text {tot }}}$ was equal to one used by Albergel et al. (2010).
Concerning ISBA-DF, the experiments were carried out using a $\mathbf{B}$ diagonal matrix with the same background standard deviation error $\sigma_{w_{n}}$ along the diagonal $\left(0.015 \mathrm{~m}^{3} \mathrm{~m}^{-3}\right)$ except that $\sigma_{w_{1}}$ was set to $0.02 \mathrm{~m}^{3} \mathrm{~m}^{-3}$. The values were adjusted to obtain results not too different from those with ISBA-2L results on average. This representation of the $\mathbf{B}$ matrix considers that the soil layer errors are not correlated. However, in ISBA-DF LSM, the layers are linked through diffusive equations. Thus, errors in a given layer should affect the others. Several experiments described below used

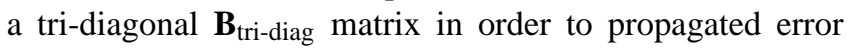
through the adjacent layers. The $\mathbf{B}_{\text {tri-diag }}$ matrix is expressed as

$\mathbf{B}_{\text {tri-diag }}=\left(\begin{array}{ccccc}\sigma_{w_{1}}^{2} & \alpha \sigma_{w_{1}} \sigma_{w_{2}} & 0 & 0 & 0 \\ \alpha \sigma_{w_{2}} \sigma_{w_{1}} & \ddots & \ddots & \ddots & 0 \\ 0 & \ddots & \sigma_{w_{n}}^{2} & \ddots & 0 \\ 0 & \ddots & \ddots & \ddots & \alpha \sigma_{w_{10}} \sigma_{w_{11}} \\ 0 & 0 & 0 & \alpha \sigma_{w_{11}} \sigma_{w_{10}} & \sigma_{w_{11}}^{2}\end{array}\right)(7)$

where the correlation term $\alpha$ is empirically set to 0.5 .

Numerous studies (Reichle and Koster, 2004; Pellarin et al., 2006; Rüdiger et al., 2007) have shown the necessity to rescale data before assimilating in situ or satellite-derived soil moisture in order to reduce systematic biases between the model and observations. In this study the cumulative distribution function (CDF)-matching technique proposed by Reichle and Koster (2004) is used for all the experiments and described in Sect. 3.1.

\subsection{Design of the experiments}

The land surface models were not calibrated. In the case of ISBA-2L, the average of the observed soil texture profile is used (i.e., $20.0 \%$ of clay and $45.3 \%$ of sand) to derive field capacity, wilting point and saturation parameters. In the case of ISBA-DF, the measured profiles of soil texture (Fig. 1a) and soil density are prescribed to the model. The value of the field capacity parameter is not prescribed in ISBA-DF.

Six assimilation experiments were undertaken. The first two were performed using ISBA-2L and ISBA-DF. Hereafter, these experiments are referred to as $2 \mathrm{~L}$ and DF-REF, respectively. The DF-REF configuration was chosen to be as close as possible to the $2 \mathrm{~L}$ configuration: the observations concerned the surface soil moisture $(0-1 \mathrm{~cm})$ equivalent and the $\mathbf{B}$ matrix was assumed diagonal for both experiments.

Then, starting from the DF-REF experiment, several modifications to the LDAS were considered. The experiment DF$\mathrm{H} 2$ assimilated SSM into the second soil layer $(1-5 \mathrm{~cm})$ in order to better represent the SSM observations gathered between 0 and $6 \mathrm{~cm}$. Next, the experiment DF-B used a nondiagonal $\mathbf{B}_{\text {tri-diag matrix in order to account for the error cor- }}$ relations in adjacent soil layers, as described in Sect. 2.3.

In addition, a bias correction technique performed before assimilation was included in the experiment DF-CDF. It 
Table 1. Description of the ISBA-DF experiments. Bold face indicates changes in the assimilation experiments with respect to ISBA-DF reference experiment (DF-REF).

\begin{tabular}{lllll}
\hline Experiment name & Assimilation & B matrix & CDF & $\begin{array}{l}\text { Local } \\
\text { precipitation }\end{array}$ \\
\hline DF-REF & layer 1 & diagonal & three years & yes \\
DF-H2 & layer 2 & diagonal & three years & yes \\
DF-B & layer 1 & non diagonal & three years & yes \\
DF-CDF & layer 1 & diagonal & yearly & yes \\
DF-NP & layer 1 & diagonal & no & no \\
\hline
\end{tabular}

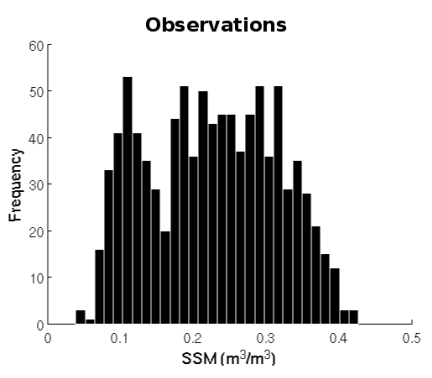

(a)

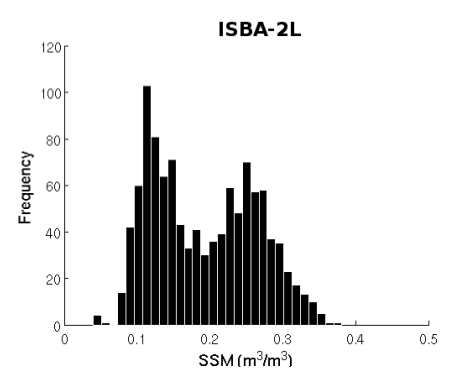

(b)

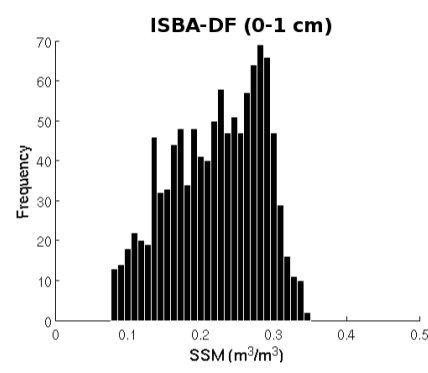

(c)

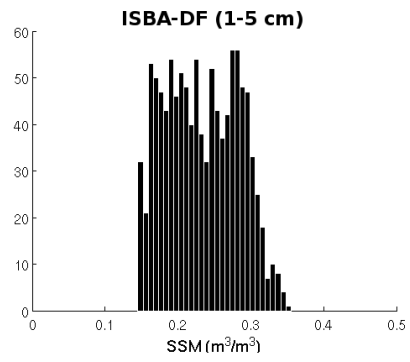

(d)

Fig. 2. (a) SSM observations $(0-6 \mathrm{~cm})$, (b) $w_{1}$ modeled by the ISBA-2L LSM, (c) $w_{1}$ and (d) $w_{2}$ simulated by ISBA-DF LSM frequency distribution at the SMOSREX site from 2003 to 2005.

allowed the impact of the temporal window chosen for data rescaling to be studied.

The last experiment, DF-NP, evaluated the benefit of assimilation in the case where ISBA-DF LSM was forced with a local forcing, which set the precipitation to zero. The role of the assimilation in LSM in compensating for a less accurate forcing will be shown below. In this experiment, the background state was not as reliable as in previous experiments since there was no precipitation. In this case, the background error $\sigma_{w_{n}}$ was increased by a factor of three (Albergel et al., 2010) and no bias correction was performed.

The CDF matching was performed for all the experiments (2L, DF-REF, DF-H2, DF-B and DF-CDF) in order to reduce systematic biases between the observations and the model, except for the DF-NP experiment. In the DF-NP experiment, CDF matching could not be performed because the open loop was too distant from the observations. For the other experiments, a CDF matching over the whole three-year period was performed. Additionally, the influence of the CDF matching on the analysis was studied with the DF-CDF experiment. In this experiment, the CDF matching was performed per year rather than over the whole three-year period.

The characteristics of the experiments are listed in Table 1.

\subsection{Assessment of the day-to-day variability of SSM}

In order to better capture the day-to-day variability of $w_{1}$, the seasonal cycle was removed by calculating monthly $w_{1}$ anomalies (Albergel et al., 2009). The difference to the mean was calculated for a sliding window of five weeks (if there were at least five measurements during this period), and the difference was scaled to the standard deviation. For each soil moisture $w_{1}$ estimate at day $(i)$, a period $F$ was defined, with $F=[i, 17 \mathrm{~d}, i+17 \mathrm{~d}]$ corresponding to a five-week window. The anomaly is dimensionless and is given by

$R_{\mathrm{ano}}=\frac{w_{1}(i)-\overline{w_{1}(F)}}{\operatorname{Stdev}\left(w_{1}(F)\right)}$.

The $R_{\text {ano }}$ values were computed for both open-loop and analysis simulations, as described in Sect. 2.4.

\section{Results}

\subsection{CDF-matching technique}

The histograms of the distributions of SSM observed at the SMOSREX site, and $w_{1}$ modeled by ISBA-2L and ISBA-DF, are displayed in Fig. 2 for the 2003-2005 period. Note that SSM observations are measured between 0 and $6 \mathrm{~cm}$ depth. The SSM observation distribution has two modes. The first corresponds to observed values smaller than $0.17 \mathrm{~m}^{3} \mathrm{~m}^{-3}$ and represents $29 \%$ of the population. The second mode concerns observed values greater than $0.17 \mathrm{~m}^{3} \mathrm{~m}^{-3}$ and represents $71 \%$ of the population. The smallest SSM observation value is equal to $0.04 \mathrm{~m}^{3} \mathrm{~m}^{-3}$ whereas the largest value reaches $0.43 \mathrm{~m}^{3} \mathrm{~m}^{-3}$. The $w_{1}$ value modeled by ISBA-2L also presents two modes. A large fraction of the $w_{1}$ population $(40 \%)$ has values smaller than $0.18 \mathrm{~m}^{3} \mathrm{~m}^{-3}$, while 

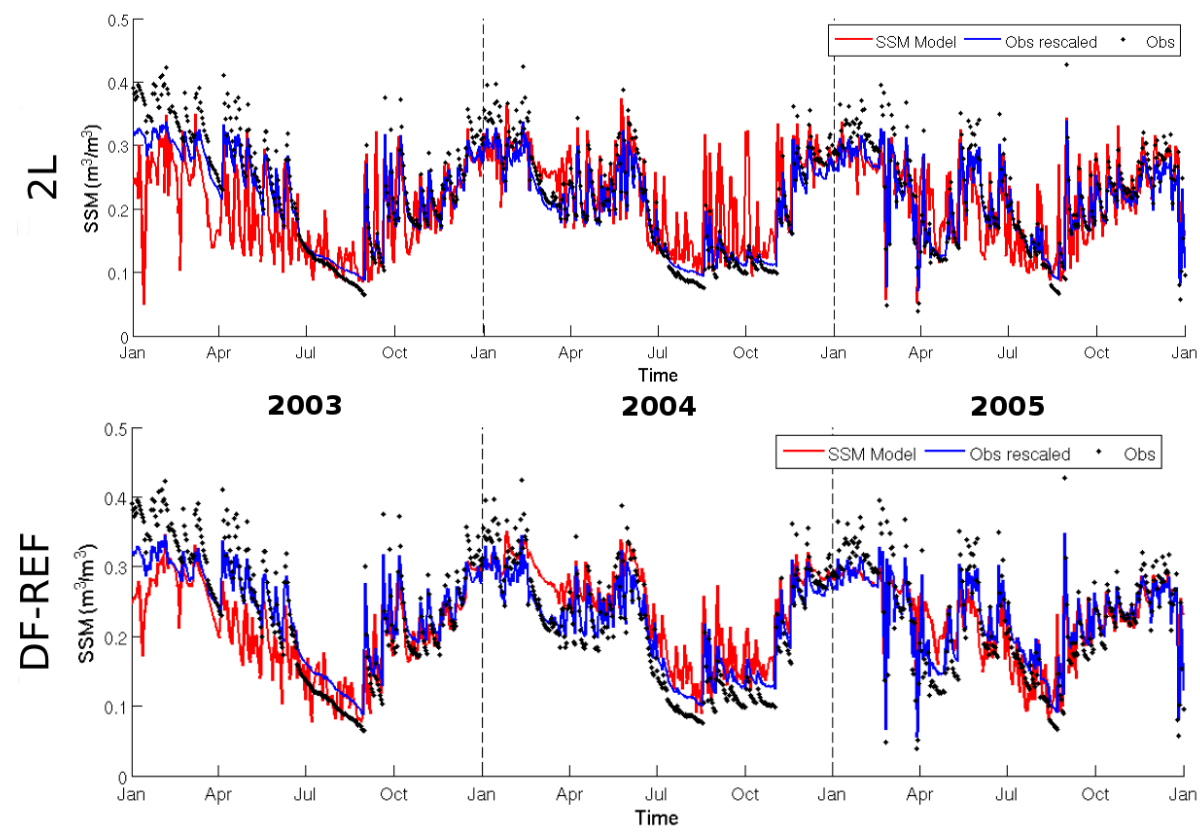

Fig. 3. Time series of SSM observations (black dots), $w_{1}$ modeled (red lines) and SSM observations rescaled after CDF matching (blue lines) for ISBA-2L (top panel) and ISBA-DF (bottom panel).

$60 \%$ of the population has values larger than this value. The smallest value of modeled $w_{1}$ is $0.04 \mathrm{~m}^{3} \mathrm{~m}^{-3}$. The largest value of $w_{1}$ computed by ISBA- $2 \mathrm{~L}$ is $0.37 \mathrm{~m}^{3} \mathrm{~m}^{-3}$. Concerning $w_{1}$ computed by ISBA-DF, the histogram of the distribution does not present two modes. The $w_{1}$ modeled with ISBA-DF has a lower dynamical range than the observations. The smallest value of $w_{1}$ modeled with ISBADF is $0.08 \mathrm{~m}^{3} \mathrm{~m}^{-3}$ and the largest is $0.35 \mathrm{~m}^{3} \mathrm{~m}^{-3}$. The values of $w_{2}$ computed by ISBA-DF have a weaker dynamic range than $w_{1}$ simulated by the same LSM. However, two modes are present. The first mode contains $54 \%$ of the population for values lower than $0.24 \mathrm{~m}^{3} \mathrm{~m}^{-3}$ and the second mode represents $46 \%$ of the population. The smallest value of the modeled $w_{2}$ is $0.014 \mathrm{~m}^{3} \mathrm{~m}^{-3}$, whereas the largest value reaches $0.36 \mathrm{~m}^{3} \mathrm{~m}^{-3}$.

The CDF matching proposed by Reichle and Koster (2004) was used in order to remove the bias between the observations and the modeled $w_{1}$. This bias correction scheme modifies the observations in order to make their statistical distribution closer to the one from the model. For this, a thirdorder polynomial fit is computed. Following Scipal et al. (2008), a large statistical sample needs to be considered to obtain a robust bias correction scheme.

The results of the CDF matching performed over this period for ISBA-2L and ISBA-DF are shown in Fig. 3. Observations rescaled with ISBA-2L and ISBA-DF do not exceed 0.34 and $0.35 \mathrm{~m}^{3} \mathrm{~m}^{-3}$, respectively. The CDF matching plays an important role during wet and dry periods and thus reduces the seasonal dynamics by decreasing the SSM values in winter and increasing them in summer.
The rationale for the application of the bias correction is that this study is a first step towards the assimilation of satellite data in ISBA-DF at regional and/or global scales. The methodology described in this paper could be used in future satellite data assimilation studies as the models were not calibrated for this site (a priori parameters are used). In such a context, systematic errors between the observations and the model have to be reduced. In situ observations are assimilated and, as explained above, systematic errors between in situ observations and model values are actually observed. The CDF-matching technique is used to reduce systematic errors.

\subsection{Assimilation experiments}

\subsubsection{L experiment}

Simulations performed without data assimilation are called "open-loop" simulations. Figure 4 shows the time series of $w_{1}, w_{\text {tot }}$ and observations for the open-loop and the analysis simulations over the period 2003-2005. The annual $w_{1}$ is generally well reproduced by the model. In winter, the modeled $w_{1}$ are smaller than the observed values, except for the winter of 2005 . The daily cycles and the rainfall responses are overestimated. The greatest differences between the open-loop and the analysis simulations concern the winter and spring of 2003 and 2004. For 2003, the analysis values are higher than the open-loop values. The contrary is seen for 2004. No marked differences between open-loop and analysis simulations are observed for 2005 . The temporal behavior of the $w_{\text {tot }}$ is well represented except for the drought 
Table 2. $w_{1}$ open-loop and analysis scores ( $r$, RMSE, SDD and bias) computed over the 3 yr period. Statistical scores are performed with rescaled observations.

\begin{tabular}{rlccccr}
\hline & Experiment & $r$ & $R_{\text {ano }}$ & $\begin{array}{c}\text { RMSE } \\
\left(\mathrm{m}^{3} \mathrm{~m}^{-3}\right)\end{array}$ & $\begin{array}{c}\text { SDD } \\
\left(\mathrm{m}^{3} \mathrm{~m}^{-3}\right)\end{array}$ & $\begin{array}{r}\text { Bias } \\
\left(\mathrm{m}^{3} \mathrm{~m}^{-3}\right)\end{array}$ \\
\hline \multirow{2}{*}{ Open-loop } & 2L & 0.69 & 0.46 & 0.066 & 0.054 & -0.016 \\
& DF-REF & 0.79 & 0.60 & 0.055 & 0.055 & -0.003 \\
\hline \multirow{5}{*}{ Analysis } & 2L & 0.74 & 0.46 & 0.052 & 0.037 & 0.015 \\
& DF-REF & 0.87 & 0.62 & 0.032 & 0.028 & -0.004 \\
& DF-CDF & 0.90 & 0.61 & 0.029 & 0.025 & -0.004 \\
& DF-H2 & 0.87 & 0.62 & 0.033 & 0.020 & -0.013 \\
& DF-B & 0.88 & 0.62 & 0.031 & 0.016 & -0.004 \\
& DF-NP & 0.86 & 0.69 & 0.038 & 0.021 & -0.016 \\
\hline
\end{tabular}
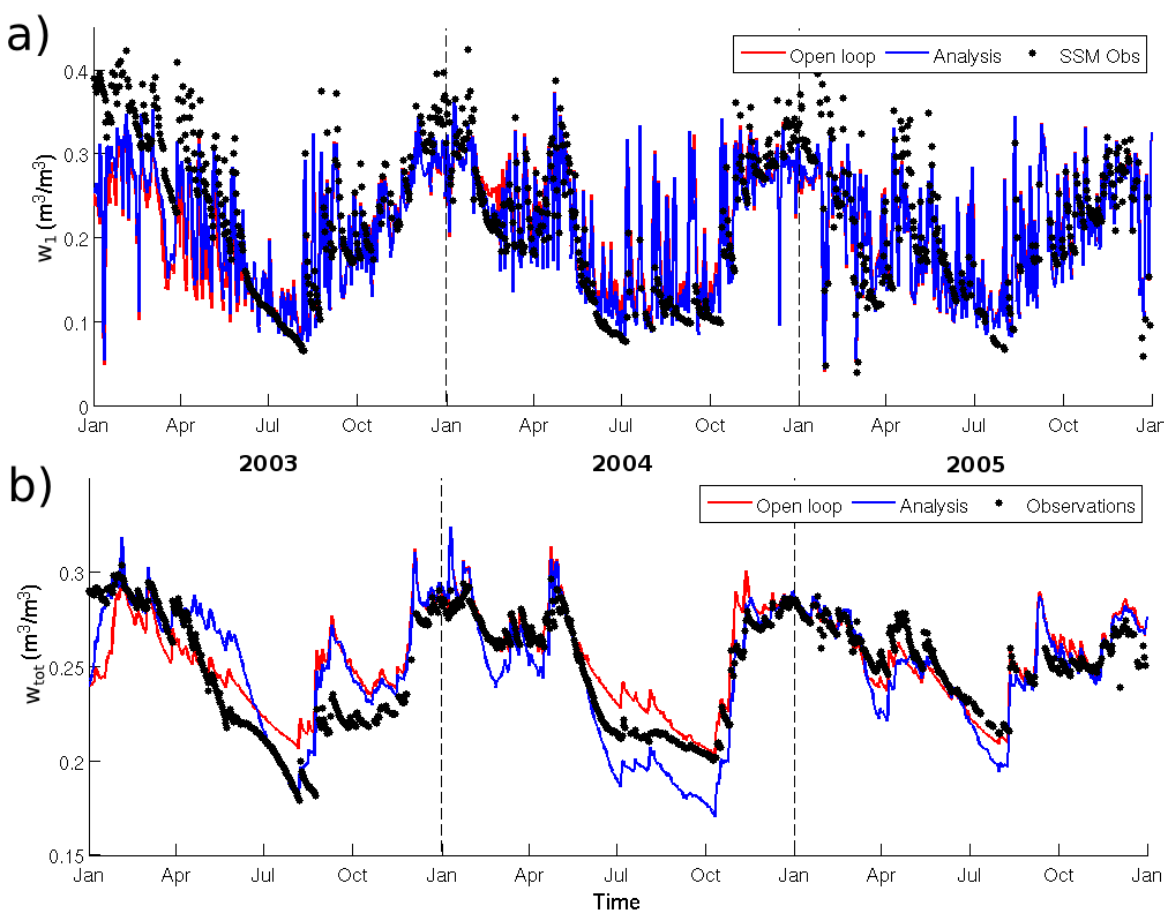

Fig. 4. 2L time series of open-loop simulation (red line), analysis simulation (blue line) and SSM observations at the SMOSREX site (black dots) for 2003-2005: in the surface layer (a) and in the total reservoir (b). The units are in $\mathrm{m}^{3} \mathrm{~m}^{-3}$.

of 2003. During the 2003 heat wave, the open-loop simulation shows larger soil moisture content values than were observed. The assimilation reduces the bias, allowing a better match with observations in this period. During the summers of 2004 and 2005, the assimilation tends to decrease the soil water content.

Several statistical scores (correlation coefficient $r$, root mean square error (RMSE), standard deviation difference (SDD) and bias (model minus observations)) for the openloop and the analysis $w_{1}$ simulations over the 3 yr period are summarized in Table 2 . Over the $3 \mathrm{yr}$ period, the $w_{1}$ analysis simulation is better correlated with the observations than the $w_{1}$ open-loop.
The annual open-loop and analysis statistical scores for $w_{\text {tot }}$ are given in Fig. 5. Assimilating SSM slightly increases the correlation coefficient and decreases the RMSE.

The Jacobian terms $\frac{\partial w_{1}(t)}{\partial w_{1}\left(t_{0}\right)}$ and $\frac{\partial w_{1}(t)}{\partial w_{\text {tot }}\left(t_{0}\right)}$ in the first thin layer and in the bulk reservoir are illustrated in Fig. 6. Generally, the Jacobian terms have positive values. Zero and small negative values are also found, which represent 39 and $15 \%$ of the Jacobian terms for $w_{1}$ and $w_{\text {tot }}$, respectively. Over the 2003-2005 period, 14 and $13 \%$ of the Jacobian terms $\frac{\partial w_{1}(t)}{\partial w_{1}\left(t_{0}\right)}$ and $\frac{\partial w_{1}(t)}{\partial w_{\text {tot }}\left(t_{0}\right)}$, respectively, are strictly equal to zero. Null Jacobian values indicate that neither $w_{1}$ nor $w_{\text {tot }}$ is sensitive to SSM assimilation. During wet periods, the Jacobian term for $w_{1}$ is equal or close to zero. For dry soils, SSM assimilation 

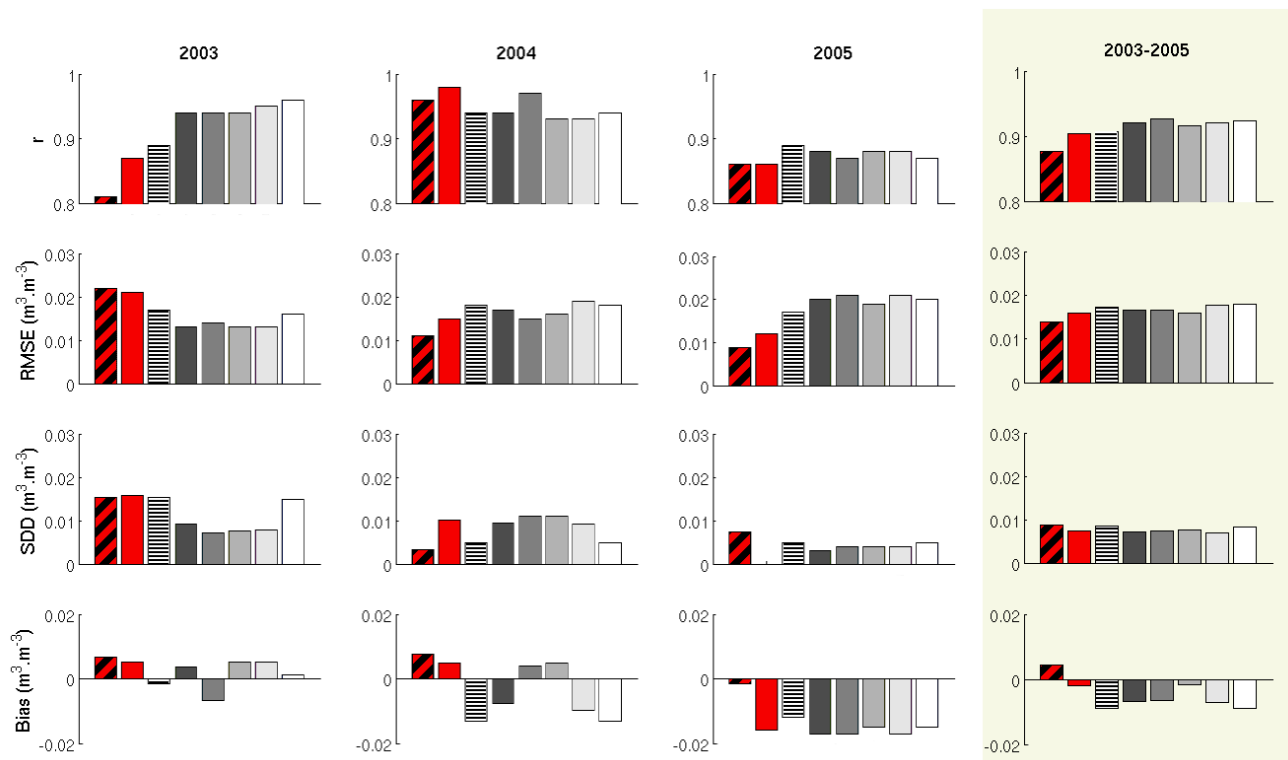

ZO.L. 2L $\square$ 2L $\boxminus$ O.L. DF $\square$ DF-REF $\square$ DF-CDF $\square$ DF-H2 $\square$ DF-B $\square$ DF-NP

Fig. 5. Yearly and $3 \mathrm{yr}$ period statistical scores for $w_{\text {tot }}$ analysis for experiments presented in Table 1 and $2 \mathrm{~L}$ experiment. O.L. means open-loop simulations.

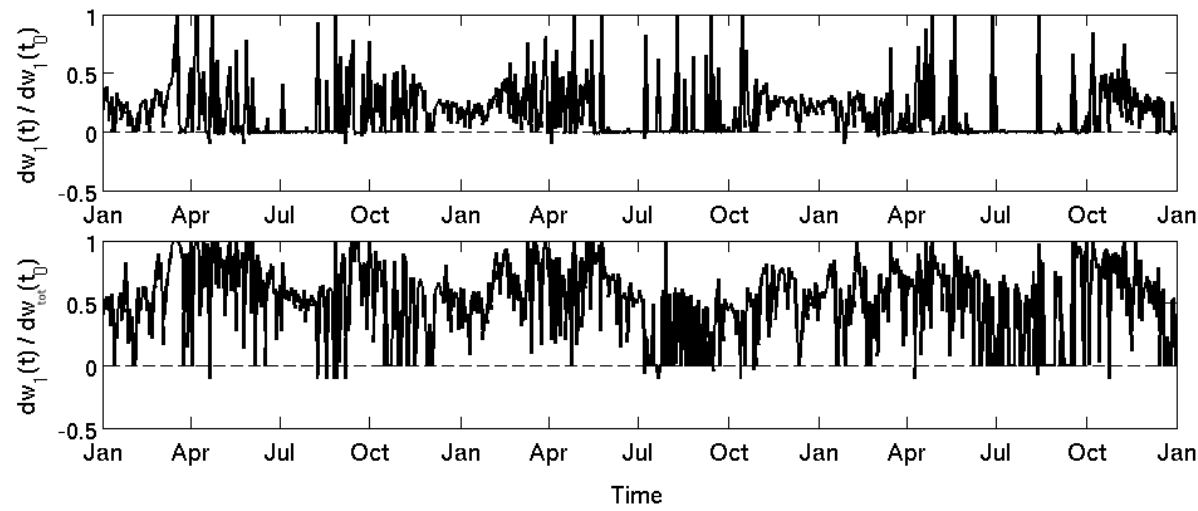

Fig. 6. Time evolution of the two Jacobian terms of ISBA-2L in the first layer (top panel) and the bulk reservoir (bottom panel).

over a $24 \mathrm{~h}$ window does not modify the behavior of $w_{1}$. The mean values of the Jacobian term with respect to $w_{1}$ and $w_{\text {tot }}$ are 0.15 and 0.51 , respectively. Over a $24 \mathrm{~h}$ window, the impact of the SSM assimilation is higher in the bulk reservoir than in the first layer. This finding is consistent with previous studies, e.g., by Draper et al. (2009) and Mahfouf (2010).

\subsubsection{DF-REF experiment}

Figure 7 shows $w_{1}$ open-loop and analysis time series for DF-REF together with observations for 2003-2005. The statistical scores for $w_{1}$ open-loop and analysis simulations over the $3 \mathrm{yr}$ period are listed in Table 2 . The $w_{1}$ simulations performed with and without assimilation are better correlated with observations for ISBA-DF than ISBA-2L. Moreover, for both open-loop and analysis simulations obtained with ISBA-DF, the day-to-day variability is reduced compared to ISBA-2L simulations. This effect tends to decrease the RMSE by 17 and $38 \%$, respectively, for the open-loop and analysis simulations computed by ISBA-DF relative to those simulated by ISBA-2L. Moreover, it is found that the analysis simulation slightly improves $R_{\text {ano }}$ in the case of ISBADF (0.62 against 0.60$)$ and has no impact on this score in the case of ISBA-2L ( 0.46 for both open-loop and analysis simulations).

The yearly $w_{\text {tot }}$ open-loop and analysis time series are shown in Fig. 7. The statistical scores are displayed in Fig. 5. For both open-loop and analysis simulations, the annual cycles are well represented by ISBA-DF and the statistical scores outperform those obtained by ISBA-2L. On the one 

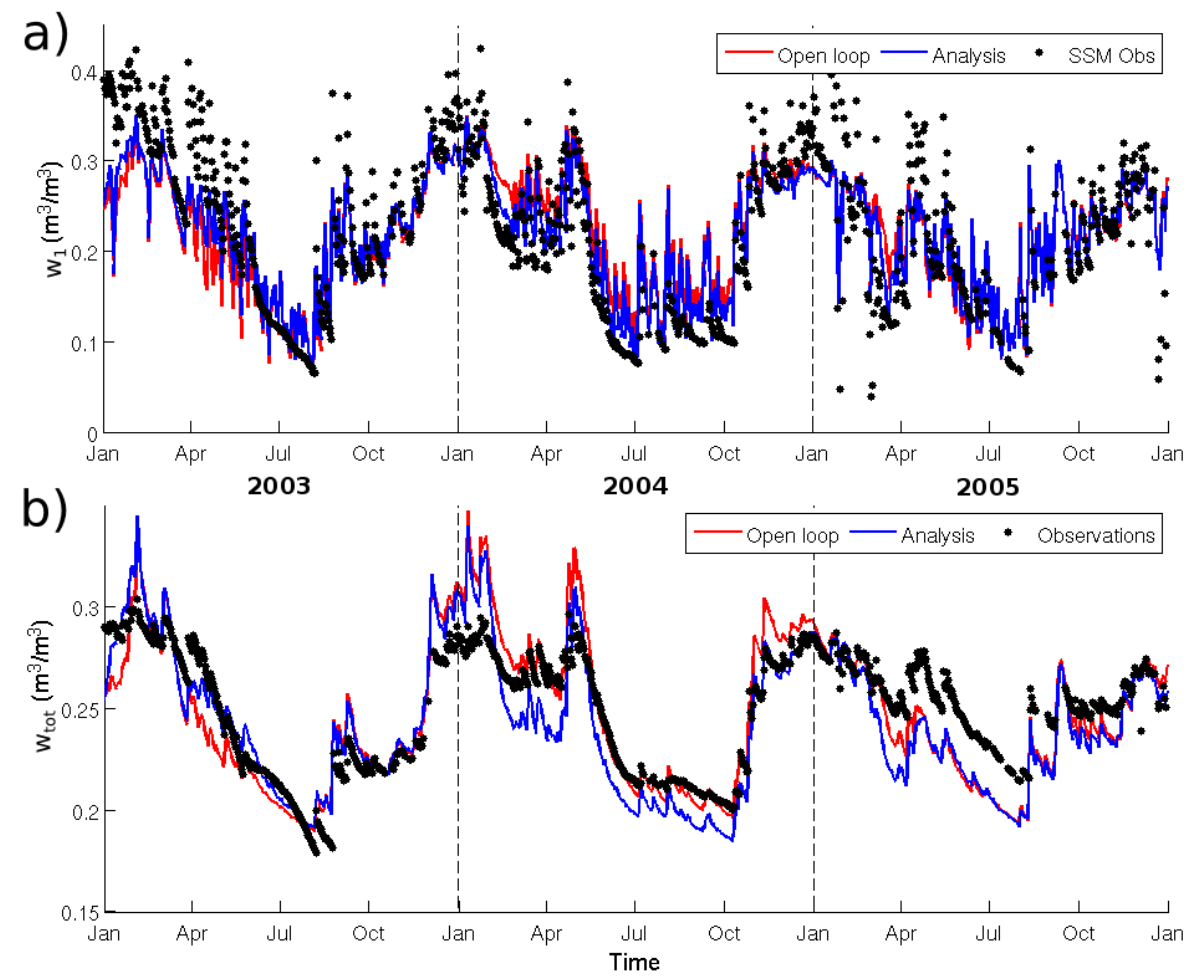

Fig. 7. DF-REF time series of open-loop simulation (red line), analysis simulation (blue line) and SSM observations at the SMOSREX site (black dots) for 2003-2005: in the surface layer (a) and in the total reservoir (b). The units are in $\mathrm{m}^{3} \mathrm{~m}^{-3}$.

hand, unlike the ISBA-2L simulations, the open-loop simulation reproduces the 2003 drought well and a perfect match with observations is noted during summer 2004. On the other hand, the open-loop root zone soil moisture is underestimated in 2005 in contrast to the ISBA-2L results. In 2003, the root zone soil moisture obtained after assimilation is closer to the observed values than that in the open-loop results. During the spring of 2004 and 2005 and the summer of 2004, the SSM observations are drier than the model counterpart values, even after CDF matching. This results in a large decrease in surface soil moisture content after assimilation.

Figure 8 shows the $w_{1}$ open-loop and analysis for four different layers $i$ : layer $2(1-5 \mathrm{~cm})$, layer $4(15-25 \mathrm{~cm})$, layer 6 $(35-45 \mathrm{~cm})$ and layer $8(35-45 \mathrm{~cm})$. For $w_{2}$ and $w_{4}$, the openloop and analysis represent the annual cycle well. After assimilation, $w_{2}$ and $w_{4}$ are better correlated with observations and the bias is smaller for the $w_{2}$ analysis than for the open-loop by $0.004 \mathrm{~m}^{3} \mathrm{~m}^{-3}$. Concerning $w_{6}$ and $w_{8}$, the annual cycle is overestimated compared to the observations. For the whole year 2005, open-loop and analysis $w_{6}$ and $w_{8}$ are found to be very dry. The same behavior is observed during the summer of 2004 . From layer $7(-45 \mathrm{~cm})$, assimilation decreases the statistical scores slightly.

The Jacobian, the Kalman gain $\mathbf{K}$ and analysis increments permit the performance of the data assimilation to be evaluated. Figure 9 shows the time evolution of the Jacobian terms $\frac{\partial w_{1}(t)}{\partial w_{n}\left(t_{0}\right)}$, the Kalman gain and the increments for each layer $n$.

The largest Jacobian values are obtained for the layers 2 and 3 (i.e., depths of $1-15 \mathrm{~cm}$ ). The mean Jacobian values for these layers are $0.19,0.28$ and 0.15 , respectively. For deeper layers, the mean Jacobian value is lower than 0.10 . The assimilation does not play an important role in the first layer or in layers 5 to 11 . During wet periods, the Jacobian in the full soil column is small but not strictly equal to zero. The Kalman gain behaves similarly. During dry periods, the information from the surface does not penetrate very deeply into the soil (less than during wet periods). However, the information from the surface affects the top layers of the soil $(1-15 \mathrm{~cm})$ more intensely than during wet periods. The Jacobian values (Fig. 9) show a decoupling of surface layers from deeper layers during dry periods, in relation to lower values of the hydraulic conductivity. From the Kalman gain value, and in contrast to $2 \mathrm{~L}$, the LDAS does not perform corrections over the total soil column but in individual layers that vary with the seasonal cycle. Note that the sum of the Jacobian values in each layer is, on average, close to the average of the sum of the Jacobian in the two layers used in $2 \mathrm{~L}$.

The analysis increments allow the impact of the data assimilation on the water mass balance to be investigated. During the summers of 2003 and 2005, only the ten first centimeters of soil are sensitive to the assimilation. For the 

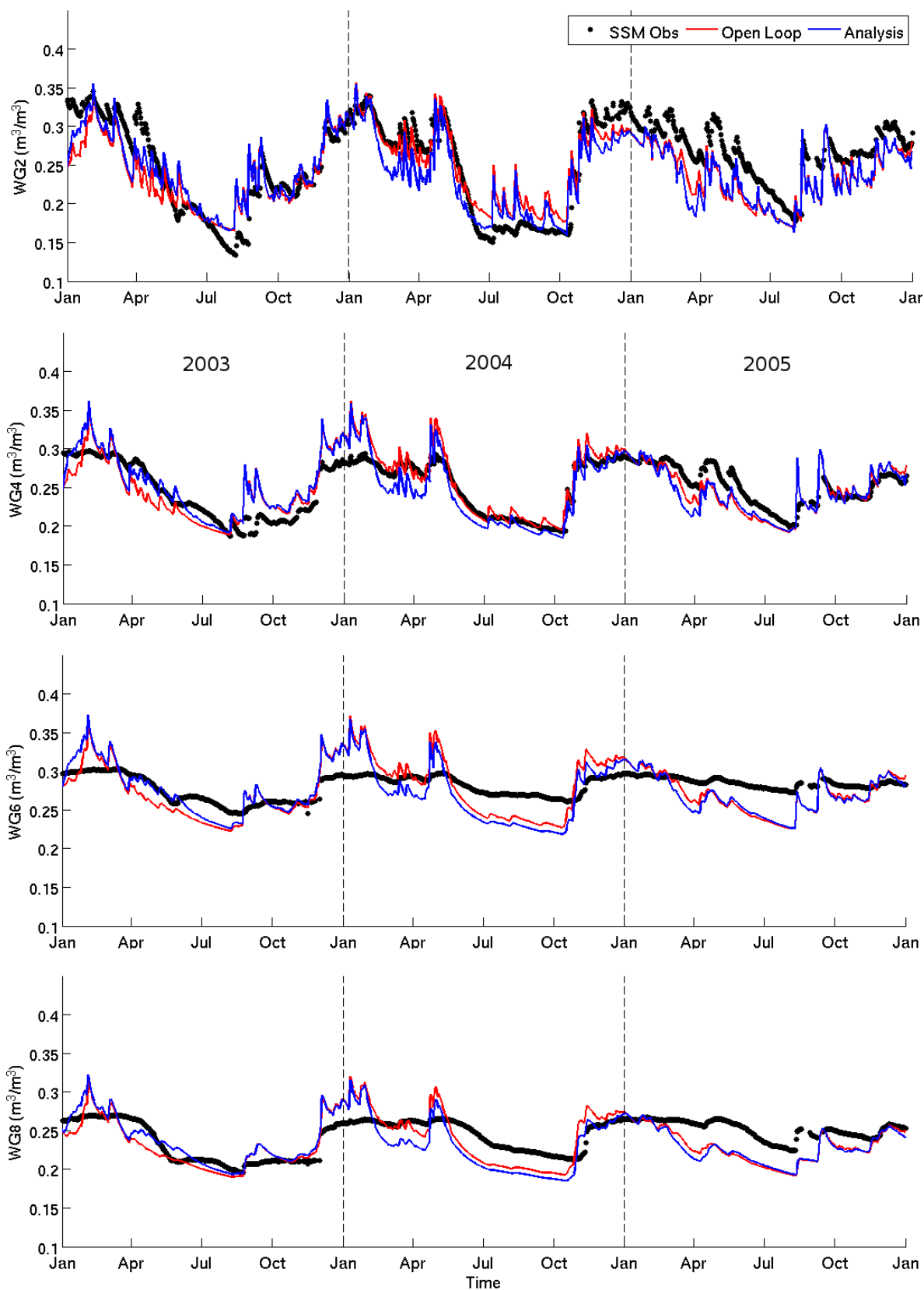

Fig. 8. Time series of soil moisture observations (black dots), soil moisture open-loop simulation (red lines) and soil moisture analysis simulation (blue lines) for four layers: layer $2: 1-5 \mathrm{~cm}$ (top row), layer 4: 15-25 cm (second row), layer 6: $35-45 \mathrm{~cm}$ (third row) and layer 8: $35-45 \mathrm{~cm}$ (bottom row).

whole year $2004,73 \%$ of the increments are negative. As a result, the assimilation tends to remove water in most instances. For example, from January to May 2004, the increments are essentially negative. In layers 1 to 5 (from the surface to $-35 \mathrm{~cm}), 87 \%$ of the increments are different from zero. For deeper layers, the fraction of non-zero increments decreases, to reach $35 \%$ for the last layer.

\subsection{Sensitivity studies in ISBA-DF}

In this section, results of the four experiments presented in Table 1 are examined.

\subsubsection{Second soil layer assimilation}

The SSM observations are measured between the surface and $6 \mathrm{~cm}$ depth. In contrast to the previous experiments, DF-H2 was carried out in order to assimilate SSM in the second layer 

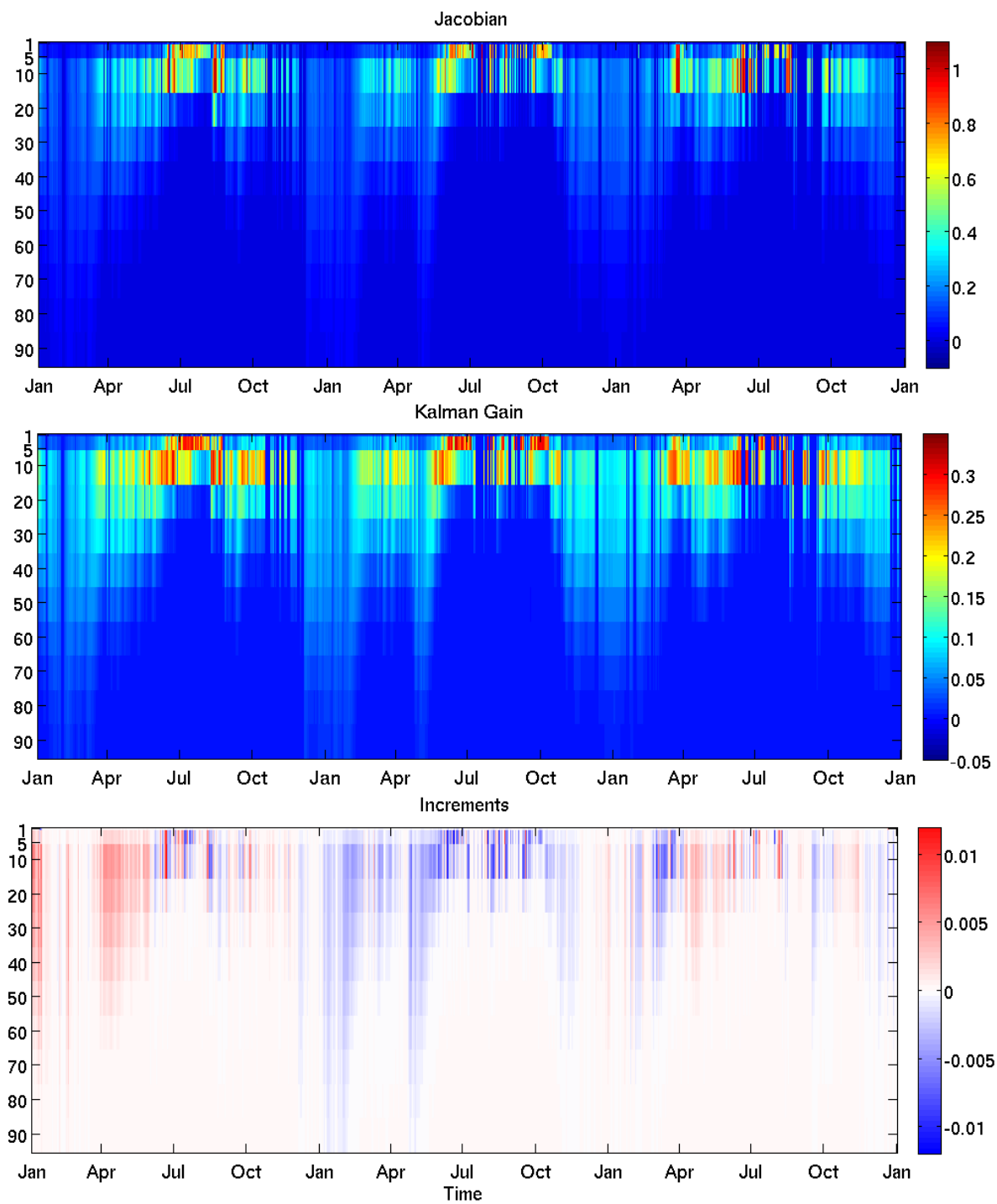

Fig. 9. Representation of the Jacobian (top panel), the Kalman gain (middle panel) and increments (bottom panel) provided by the SSM assimilation for DF-REF. Soil layer depths (in $\mathrm{cm}$ ) are represented on the left-hand side $y$ axis and time is represented on the $x$ axis.

of ISBA-DF. The depth of this layer $(1-5 \mathrm{~cm})$ is closer to the observation depth. CDF matching is performed between $w_{2}$ and the observations over the 3 yr period to remove systematic biases.

Statistical scores of $w_{1}$ analysis for the $3 \mathrm{yr}$ period are displayed in Table 2. Over time, the assimilation in the second layer tends to decrease the RMSE of the $w_{1}$ with respect to the DF-REF. However, the correlation coefficient of $w_{1}$ computed by DF-H2 is weaker than that simulated by DF-REF.

Yearly statistical scores of $w_{\text {tot }}$ are shown in Fig. 5. The RMSE of root zone soil moisture is slightly smaller for the analysis using DF-H2 than DF-REF. Over the full period, assimilating SSM in the second layer decreases the bias by $84 \%$ compared to DF-REF. The non-zero increments increase by $3 \%$ for deeper layers $(-35$ to $-95 \mathrm{~cm})$ with respect to the reference experiment. For layers 1 to 5, no significant impact is observed.

Figure 10 shows the time evolution of $w_{2}$ open-loop and the Jacobian term $\frac{\partial w_{2}(t)}{\partial w_{2}\left(t_{0}\right)}$ for DF-H2 and $\frac{\partial w_{1}(t)}{\partial w_{2}\left(t_{0}\right)}$ for DF-REF. For both experiments, the Jacobian is larger during dry periods than during wet periods. In the wet season (winter) and for rainy events, the Jacobians are very low, indicating that initial soil moisture perturbations are lost during the $24 \mathrm{~h}$ model integration. In such situations, the soil moisture in the first two layers is therefore mostly driven by the atmospheric forcing. As seen in Fig. 10, the Jacobian $\frac{\partial w_{1}(t)}{\partial w_{2}\left(t_{0}\right)}$ is more sensitive to rainfall events when the SSM is assimilated in the first layer than in the second layer. Since the second layer is less impacted by the atmospheric forcing than the first layer, assimilating the observations in the second layer overcomes 

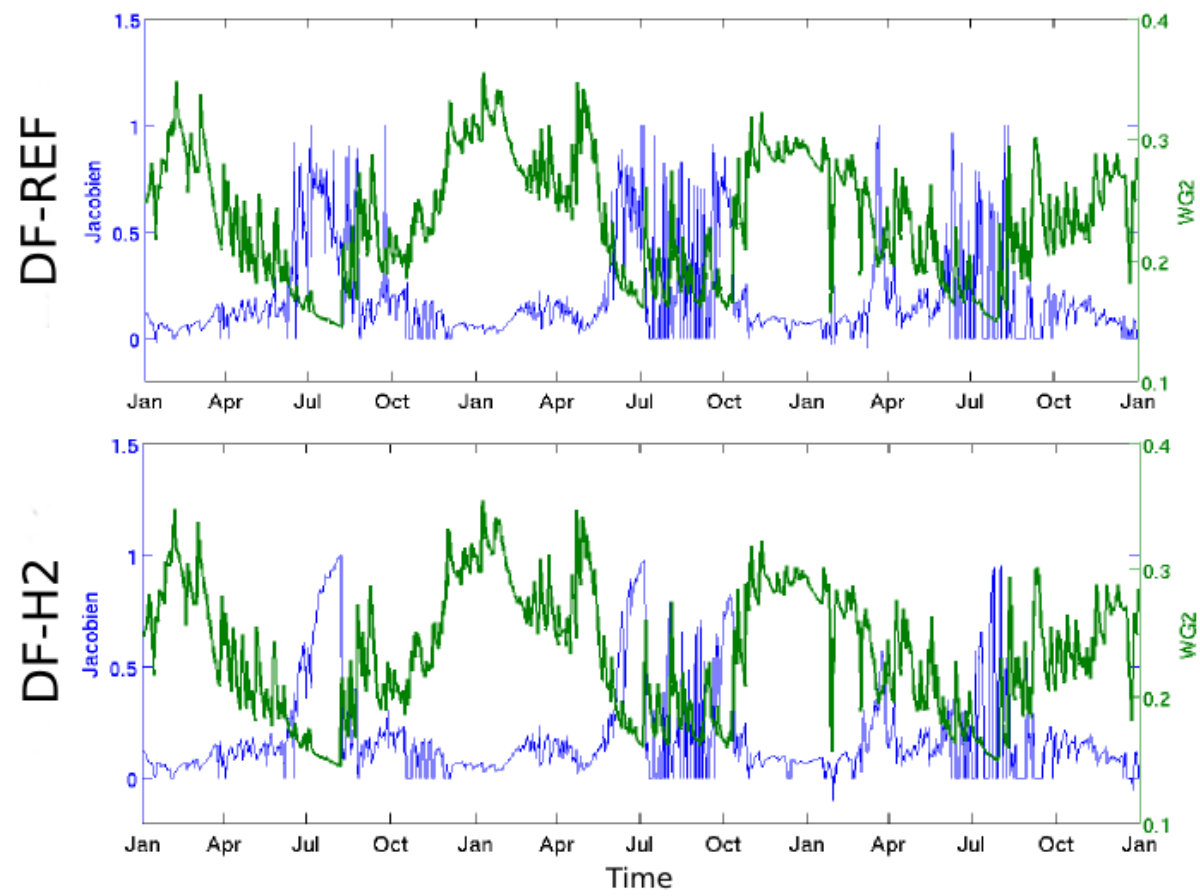

Fig. 10. Time evolution of $w_{2}$ using ISBA-DF LSM in the second layer (green line) and the Jacobian values (blue line): $\frac{\partial w_{1}(t)}{\partial w_{2}\left(t_{0}\right)}$ in DF-REF (top panel) and $\frac{\partial w_{2}(t)}{\partial w_{2}\left(t_{0}\right)}$ in DF-H2 (bottom panel).

the effect of rainfall events and allows more information to be extracted.

\subsubsection{The choice of the $B$ matrix}

Experiment DF-B was undertaken with the $\mathbf{B}_{\text {tri-diag }}$ matrix in order to propagate model error in adjacent layers. The statistical scores of $w_{1}$ analysis over the $3 \mathrm{yr}$ period are displayed in Table 2. Compared to DF-REF, a slight increase in the correlation coefficient and a decrease in RMSE are observed. The SDD falls by $42 \%$ relative to the reference experiment. Yearly statistical scores of $w_{\text {tot }}$ analysis are shown in Fig. 5. Statistical scores of DF-REF and DF-B are close.

The $\mathbf{B}_{\text {tri-diag }}$ matrix has an important impact on the Kalman gain. Figure 11 shows the difference between the Kalman gain computed by the assimilation in DF-B and DF-REF. Adding correlation terms to the $\mathbf{B}$ matrix increases the Kalman gain values from 1 to $35 \mathrm{~cm}$ depth and for deeper layers during wet periods. For these layers during dry periods, the Kalman gain is strictly zero in DF-REF. Over the 3 yr period, the mean Kalman gain values increase by $27 \%$ in the DF-B relative to DF-REF.

An assimilation experiment with a five-band $\mathbf{B}$ matrix was also performed to increase vertical correlations (not shown). The statistical scores of $w_{\text {tot }}$ analysis over the $3 \mathrm{yr}$ period were close to those obtained with DF-B. However, the average Kalman gain values increased by $21 \%$ with respect to DF-B.

\subsubsection{Impact of the CDF matching on the water mass balance}

In this section, the impact of CDF matching on the water mass balance is investigated. CDF matching per year is computed in the experiment DF-CDF but not in DF-REF. A thirdorder polynomial fit is computed for each individual year. Figure 12 shows the CDF for the SSM observations, modeled $w_{1}$, and SSM rescaled observations for 2003, 2004 and 2005. Generally, CDF matching reduces the dynamical range of the observations. Concerning 2003, only the largest values are reduced. For 2004, dry SSM observations (below $0.30 \mathrm{~m}^{3} \mathrm{~m}^{-3}$ ) are increased to match to the modeled $w_{1}$. The same feature is seen for 2005: the observation values are augmented until $0.27 \mathrm{~m}^{3} \mathrm{~m}^{-3}$ and reduced for dry values. CDF matching performed over the $3 \mathrm{yr}$ period is also shown in Fig. 12. The SSM CDF in 2003 and 2004 do not have the same features as the CDF performed over the three years. Therefore, rescaled SSM in 2003 and 2004 will be different from SSM rescaled with the CDF matching performed over the 3 yr period.

The $w_{1}$ analysis statistical scores performed with DF-CDF are displayed in Table 2. The correlation of $w_{1}$ increases by $14 \%$ with respect to the open-loop simulation. Compared to DF-REF $w_{1}$ analysis, a slight increase $(3 \%)$ of the correlation coefficient is noted. The RMSE decreases by $47 \%$ with respect to the open-loop simulation and by $10 \%$ relative to $w_{1}$ analysis simulation computed with DF-REF. 


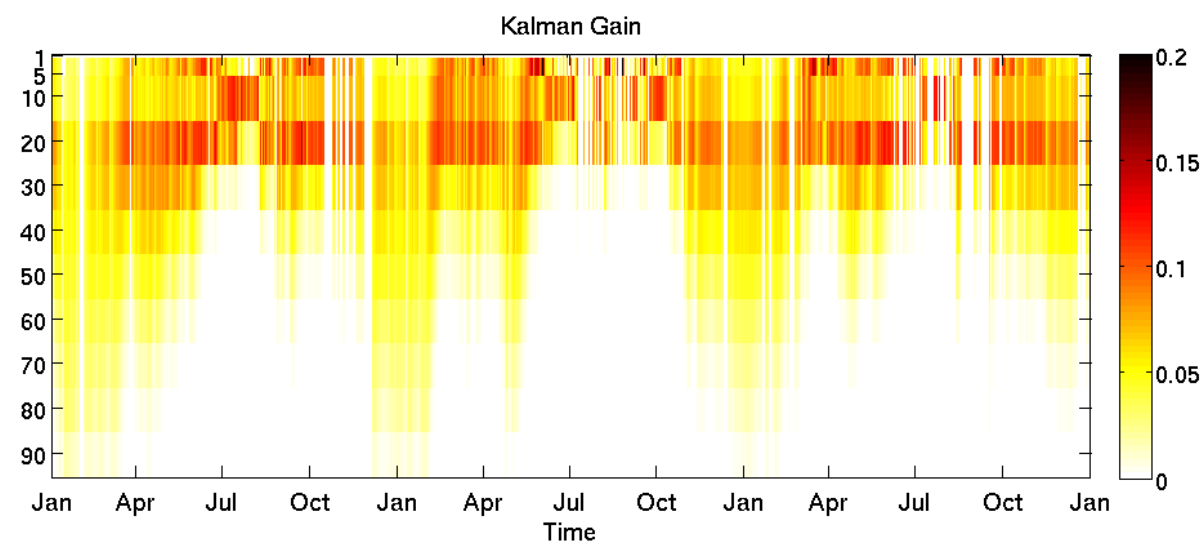

Fig. 11. Difference of the Kalman gain provided by the SSM assimilation in DF-B and DF-REF. Soil layer depths (in cm) are represented on the left-hand side $y$ axis and time is represented on the $x$ axis.
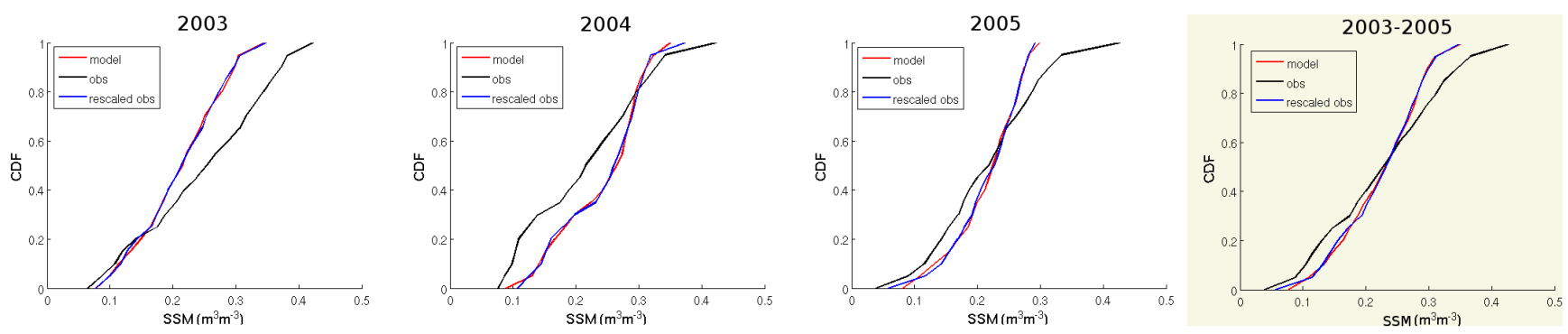

Fig. 12. CDF matching between $w_{1}$ modeled with ISBA-DF LSM and SSM observations for 2003, 2004, 2005 and the 3 yr period.

Over the $3 \mathrm{yr}$ period, the correlation coefficient, RMSE, SDD and bias values of the $w_{\text {tot }}$ analysis are 0.90, 0.052, 0.052 and $-0.006 \mathrm{~m}^{3} \mathrm{~m}^{-3}$, respectively. A slight increase of the statistical scores is noted with respect to DF-REF (Fig. 5). The main difference between DF-REF and DF-CDF is obtained during 2004 where the RMSE of $w_{\text {tot }}$ decreases by $13 \%$.

The increments provided by the assimilation scheme using CDF matching per year are shown in Fig. 13. For 2005, no significant differences are observed. However, for 2003 and 2004, differences between increments obtained with DFREF and DF-CDF are clear. Using an annual CDF allows the water mass balance to be conserved in the root zone. For example, in 2003, water from the root zone is removed between January and April in DF-CDF whereas water is still added during the same period in DF-REF. The same feature is observed during the full year of 2004: water in the soil is systematically removed in several consecutive months in DF-REF but in DF-CDF, significant water amounts are added. Moreover, using annual CDF matching improves the simulation of the root zone soil moisture for the years when the SSM distribution is very different from the average SSM distribution.

\subsubsection{Forcing without precipitation}

Removing precipitation from the forcing permits the benefit of the SSM assimilation to be evaluated when the forcing is not accurate. No CDF-matching technique is used over the assimilated SSM. The statistical scores of $w_{1}$ analysis are shown in Table 2. The statistical scores are improved compared to those of DF-REF. For example, the correlation coefficient is increased by $9 \%$ and the RMSE is decreased by $43 \%$ with respect to the open-loop reference experiment.

The statistical scores computed per year for $w_{\text {tot }}$ analysis are displayed in Fig. 5. Despite the lack of precipitation in the forcing, statistics are close to the DF-REF open-loop simulation. Good statistical results are due to the increase in the background error in DF-NP with respect to DF-REF.

Time series of the root zone soil moisture with and without assimilation for the experiment DF-NP are shown in Fig. 14. Without precipitation, $w_{\text {tot }}$ simulated by the openloop goes down while the analysis simulation maintains the annual cycle.

From an operational point of view, the SSM assimilation in ISBA-DF LSM allows forcing uncertainties to be overcome, even though the current test was performed in extreme conditions. 


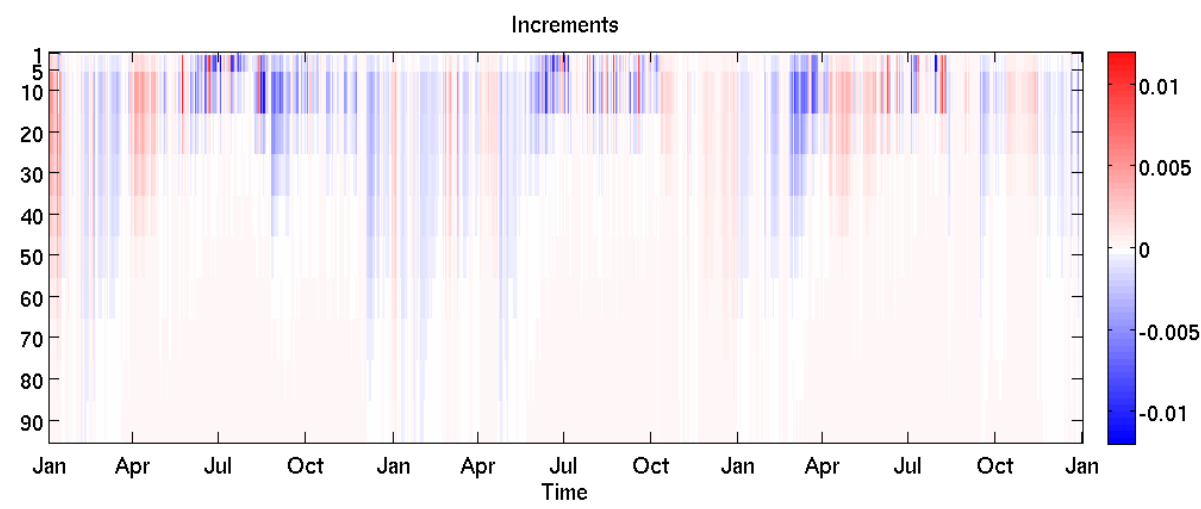

Fig. 13. Representation of daily increments $\left(\mathrm{m}^{3} \mathrm{~m}^{-3}\right)$ provided by the SSM assimilation in DF-CDF with a per year CDF matching. Soil layer depths (in $\mathrm{cm}$ ) are represented on the left-hand side $y$ axis and time on the $x$ axis.

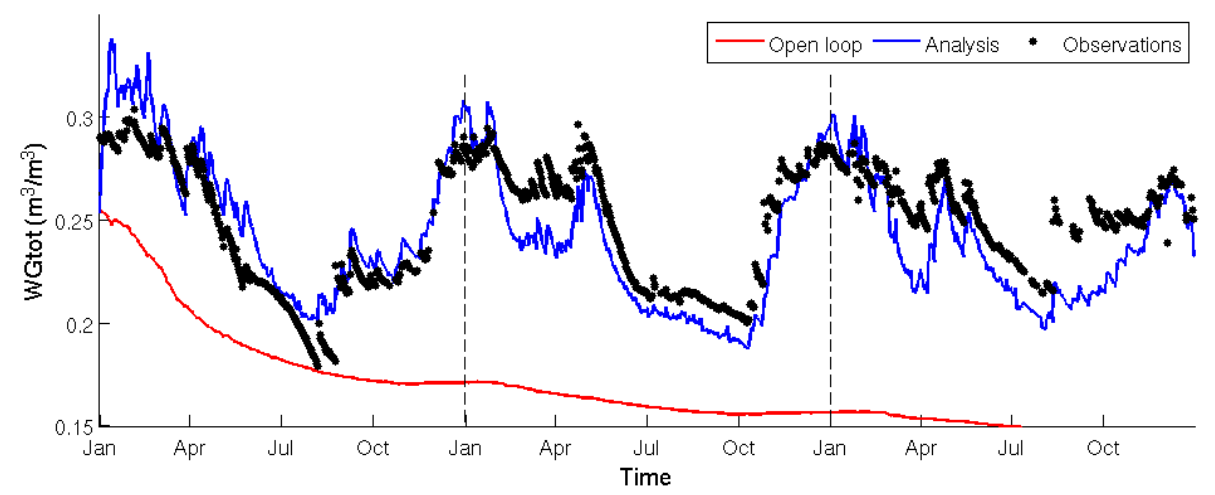

Fig. 14. Time series of root zone soil moisture observations (black dots), soil moisture open-loop simulation (red lines) and soil moisture analysis simulation (blue lines) computed with the experiment DF-NP.

\section{Discussion}

The ISBA-2L LSM is used for operational NWP predictions at Météo-France and has been widely studied. At the moment, unlike ISBA-2L, ISBA-DF is a new LSM that is starting to be tested and is used only for research applications. Soil moisture computed by ISBA-DF is better correlated with observations than that simulated by ISBA-2L. This result is consistent with the finding of Decharme et al. (2011) on the fallow part of the SMOSREX site. Over the $3 \mathrm{yr}$ period, an improvement in terms of statistical scores is found for both $w_{1}$ and $w_{\text {tot }}$ when simulated by ISBA-DF rather than ISBA-2L.

The SSM assimilation improves the modeling of $w_{1}$ and $w_{\text {tot }}$ for the two LSMs. In $2 \mathrm{~L}$, corrections introduced by the assimilation affect the whole root zone. This feature is not realistic, particularly for a bare soil surface (Draper et al., 2009). The propagation of SSM information to deeper soil layers is consistent with the water transfer physics in ISBA-DF. The assimilation does not have the same impact on the soil moisture content at different soil depths. For example, during dry periods, corrections introduced by the LDAS are located at depths between 1 and $15 \mathrm{~cm}$. Weaker corrections were found to impact the total soil column during wet periods.

As seen in the previous sections, for all the experiments carried out with ISBA-DF LSM, the assimilation of SSM has little impact in the first layer $(0-1 \mathrm{~cm})$. For example, the mean Jacobian $\frac{\partial w_{1}(t)}{\partial w_{1}\left(t_{0}\right)}$ for DF-REF is equal to 0.034 in the first layer. In contrast, the mean Jacobians $\frac{\partial w_{1}(t)}{\partial w_{2}\left(t_{0}\right)}, \frac{\partial w_{1}(t)}{\partial w_{3}\left(t_{0}\right)}$ and $\frac{\partial w_{1}(t)}{\partial w_{4}\left(t_{0}\right)}$ are larger than 0.1. In the case of ISBA-DF, small Jacobian values are obtained for the top soil layer. Due to the small size of the $w_{1}$ reservoir $(1 \mathrm{~cm})$, the dynamics of the first layer is driven by the atmospheric forcing to a large extent. Moreover, in the experimental setup, the length of the assimilation window is $24 \mathrm{~h}$. Over this time period, the impact of the initial conditions is reduced by the atmospheric forcing. Similar results were found with DF-H2 with small values of the Jacobians in the first layer. This result is in agreement with a recent study by Medina et al. (2012), also showing a weak impact of the Kalman filter in the first layer.

Accounting for vertical correlations in the background error covariance matrix, $\mathbf{B}_{\text {tri-diag }}$, of the SEKF scheme tends to decrease the RMSE of $w_{1}$. Despite an increase in Jacobian and Kalman gain values, no significant improvement to the 
analysis of $w_{\text {tot }}$ has been noticed. In future studies, it would be desirable to work with an EKF scheme instead of an SEKF to benefit from the evolution of the $\mathbf{B}$ matrix. An evolutive $\mathbf{B}$ matrix would take the vertical correlation errors into account better. However, more research needs to be done to improve the specification of model errors. Assimilating SSM in the second layer appears to be more physically meaningful.

After assimilation of SSM in the second layer, the bias of $w_{\text {tot }}$ analysis is small. Over the 3 yr period, DF-H2 appears to be the best experiment in terms of RMSE and bias.

Numerous studies have proposed to rescale the observations before assimilating them into an LSM. Several authors have performed CDF matching over the entire period of interest (Reichle and Koster, 2004), whereas others have used seasonal-based CDF matching (Barbu et al., 2014; Draper et al., 2009). As shown in Sect. 3, using CDF matching per year constrains the mass balance better, essentially for 2004 . In southwestern France, the yearly SSM distribution is very different from one year to another and global CDF matching erases the interseasonal variability of the model dynamics. Yearly CDF matching is advocated for reanalysis systems even though it is not suitable for real time monitoring or forecasting.

Other assimilation studies at the SMOSREX site were performed in order to improve the root zone soil moisture (Sabater et al., 2007; Albergel et al., 2010). Unlike this study, they were focused on the fallow part of the SMOSREX site. Over the bare soil, the root zone dynamics and the response to rainfall events are larger than over the fallow area. In this study, similar results to those of Sabater et al. (2007) and Albergel et al. (2010) were found using the $2 \mathrm{~L}$ model.

\section{Conclusions}

This study investigated the assimilation performances of two versions of the land surface model ISBA: (1) ISBA-2L with a soil composed of two layers and (2) ISBA-DF with a soil divided into 11 layers. This work was carried out on the SMOSREX bare soil site during the period 2003-2005. This was a first attempt to explore the potential of assimilating SSM using an SEKF over France with ISBA-DF. Regarding open-loop simulations, $w_{1}$ and $w_{\text {tot }}$ simulated by ISBA-DF outperformed those computed by ISBA-2L.

The largest impact of the SSM assimilation with ISBA-DF concerns the first $45 \mathrm{~cm}$ of soil. For dry periods, the SSM assimilation plays an important role from the surface to $15 \mathrm{~cm}$ whereas, during wet periods, weak corrections are applied for the entire soil column. These seasonal variations cannot be represented with a single bulk layer in the root zone. For the first time, the evolution of the Jacobian terms, the Kalman gain and the increments with depth have been examined.

The best improvement of $w_{\text {tot }}$ analysis was obtained by assimilating SSM in the second layer. This result shows the benefits of working with a multilayer LSM. Assimilating the SSM in the second layer and adding vertical correlation errors are recommended for future research. Yearly CDF matching leads to a better conservation of the water mass balance in the root zone and is encouraged for data reanalyses.

This work shows the potential to improve the soil moisture in the deep layers by assimilating SSM in ISBA-DF. This study will be extended to the whole of France by assimilating satellite-derived SSM such as ASCAT and SMOS. In addition, the assimilation of brightness temperature from the $\mathrm{L}$ band radiometer LEWIS in ISBA-DF would be interesting. The impact on the other terms of water balance (surface evaporation and runoff) was not examined because of the lack of suitable observations over the bare soil plot of SMOSREX.

Acknowledgements. The work of M. Parrens was supported by the French Ministry of Research and the work of Alina Barbu was supported by the IMAGINES project, which was co-funded by the European Commission within the Copernicus initiative in FP7. The SMOSREX project was co-funded by the Programme National de Télédétection Spatiale and by the Programme Terre Océan Surface Continentales et Atmosphère (CNES), and by participants in the experiments CESBIO (CNES, CNRS, IRD, UPS), CNRM-GAME (Météo-France, CNRS), INRA, and ONERA, all within the framework of the SMOS science preparatory program.

Edited by: N. Romano

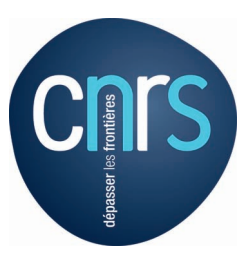

The publication of this article is financed by CNRS-INSU.

\section{References}

Albergel, C., Rüdiger, C., Carrer, D., Calvet, J.-C., Fritz, N., Naeimi, V., Bartalis, Z., and Hasenauer, S.: An evaluation of ASCAT surface soil moisture products with in-situ observations in Southwestern France, Hydrol. Earth Syst. Sci., 13, 115-124, doi:10.5194/hess-13-115-2009, 2009.

Albergel, C., Calvet, J.-C., Mahfouf, J.-F., Rüdiger, C., Barbu, A. L., Lafont, S., Roujean, J.-L., Walker, J. P., Crapeau, M., and Wigneron, J.-P.: Monitoring of water and carbon fluxes using a land data assimilation system: a case study for southwestern France, Hydrol. Earth Syst. Sci., 14, 1109-1124, doi:10.5194/hess-14-1109-2010, 2010.

Balsamo, G., Bouyssel, F., and Noilhan, J.: A simplified bidimensional variational analysis of soil moisture from screenlevel observations in a mesoscale numerical weather-prediction model, Q. J. Roy. Meteorol. Soc., 130, 895-915, 2004.

Balsamo, G., Mahfouf, J., Bélair, S., and Deblonde, G.: A land data assimilation system for soil moisture and temperature: an information content study, J. Hydrometeorol., 8, 1225-1242, 2007. 
Barbu, A. L., Calvet, J.-C., Mahfouf, J.-F., Albergel, C., and Lafont, S.: Assimilation of Soil Wetness Index and Leaf Area Index into the ISBA-A-gs land surface model: grassland case study, Biogeosciences, 8, 1971-1986, doi:10.5194/bg-8-1971-2011, 2011.

Barbu, A. L., Calvet, J.-C., Mahfouf, J.-F., and Lafont, S.: Integrating ASCAT surface soil moisture and GEOV1 leaf area index into the SURFEX modelling platform: a land data assimilation application over France, Hydrol. Earth Syst. Sci., 18, 173-192, doi:10.5194/hess-18-173-2014, 2014.

Bartalis, Z., Wagner, W., Naeimi, V., Hasenauer, S., Scipal, K., Bonekamp, H., Figa, J., and Anderson, C.: Initial soil moisture retrievals from the METOP-A Advanced Scatterometer (ASCAT), Geophys. Res. Lett., 34, L20 401, 2007.

Boone, A., Calvet, J.-C., and Noilhan, J.: Inclusion of a third soil layer in a land surface scheme using the force-restore method, J. Clim. Appl. Meteorol., 38, 1611-1630, 1999.

Crow, W. and Wood, E.: The assimilation of remotely sensed soil brightness temperature imagery into a land surface model using ensemble Kalman filtering: A case study based on ESTAR measurements during SGP97, Adv. Water Resour., 26, 137-149, 2003.

de Rosnay, P., Calvet, J.-C., Kerr, Y., Wigneron, J.-P., Lemaître, F., Escorihuela, M. J., Sabater, J. M., Saleh, K., Barrié, J., Bouhours, G., Coret, L., Cherel, G., Dedieu, G., Durbe, R., Fritz, N. E. D., Froissard, F., Hoedjes, J., Kruszewski, A., Lavenu, F., Suquia, D., and Waldteufel, P.: SMOSREX: A long term field campaign experiment for soil moisture and land surface processes remote sensing, Remote Sens. Environ., 102, 377-389, doi:10.1016/j.rse.2006.02.021, 2006.

de Rosnay, P., Drusch, M., Vasiljevic, D., Balsamo, G., Albergel, C., and Isaksen, L.: A simplified Extended Kalman Filter for the global operational soil moisture analysis at ECMWF, Q. J. Roy. Meteorol. Soc., 139, 1199-1213, doi:10.1002/qj.2023, 2013.

Deardorff, J.: A parameterization of ground-surface moisture content for use in atmospheric prediction models, J. Appl. Meteorol., 16, 1182-1185, 1977.

Decharme, B., Boone, A., Delire, C., and Noilhan, J.: Local evaluation of the Interaction between Soil Biosphere Atmosphere soil multilayer diffusion scheme using four pedotransfer functions, J. Geophys. Res., 116, D20126, doi:10.1029/2011JD016002, 2011.

Draper, C. S., Mahfouf, J.-F., and Walker, J. P.: An EKF assimilation of AMSR-E soil moisture into the ISBA land surface scheme, J. Geophys. Res., 114, D20104, doi:10.1029/2008JD011650, 2009.

Draper, C. S., Mahfouf, J.-F., Calvet, J.-C., Martin, E., and Wagner, W.: Assimilation of ASCAT near-surface soil moisture into the SIM hydrological model over France, Hydrol. Earth Syst. Sci., 15, 3829-3841, doi:10.5194/hess-15-3829-2011, 2011.

Entekhabi, D., Nakamura, H., and Njoku, E.: Solving the inverse problem for soil moisture and temperature profiles by sequential assimilation of multifrequency remotely sensed observations, IEEE T. Geosci. Remote, 32, 438-448, 1994.

Entekhabi, D., Asrar, G., Betts, A., Beven, K., Bras, R., Duffy, C., Dunne, T., Koster, R., Lettenmaier, D., McLaughlin, D., Shuttleworth, W., van Genuchten, M., Wei, M.-Y., and Wood, E.: An agenda for land surface hydrology research and a call for the second international hydrological decade, B. Am. Meteorol. Soc., 80, 2043-2058, 1999.
Entekhabi, D., Njoku, E. G., Houser, P., Spencer, M., Doiron, T., Kim, Y., Smith, J., Girard, R., Belair, S., Crow, W., Jackson, T. J., Kerr, Y. H., Kimball, J. S., Koster, R., McDonald, K. C., O’Neill, P. E., Pultz, T., Running, S. W., Shi, J. C., Wood, E., and Van Zyl, J.: The hydrosphere state (Hydros) satellite mission: an earth system pathfinder for global mapping of soil moisture and land freeze/thaw, IEEE T. Geosci. Remote, 42, 2184-2195, 2004.

Hess, R.: Assimilation of screen-level observations by variational soil moisture analysis, Meteorol. Atmos. Phys., 77, 145-154, 2001.

Houser, P. R., Shuttleworth, W. J., Famiglietti, J. S., Gupta, H. V., Syed, K. H., and Goodrich, D. C.: Integration of soil moisture remote sensing and hydrologic modeling using data assimilation, Water Resour. Res., 34, 3405-3420, 1998.

Ide, J., Courtier, P., Ghil, M., and Lorenc, A.: Unified Notation for Data Assimilation: Operational, Sequential and Variational, J. Meteorol. Soc. Jpn., 75, 181-189, 1997.

Kerr, Y., Waldteufel, P., Wigneron, J., Martinuzzi, J., Font, J., and Berger, M.: Soil moisture retrieval from space: The Soil Moisture and Ocean Salinity (SMOS) mission, IEEE T. Geosci. Remote, 39, 1729-1735, 2001.

Koster, R. and Suarez, M.: Relative contributions of land and ocean processes to precipitation variability, J. Geophys. Res., 100, 13775-13790, 1995.

Lemaître, F., Poussière, J.-C., Kerr, Y. H., Déjus, M., Durbe, R., de Rosnay, P., and Calvet, J.-C.: Design and test of the groundbased L-band radiometer for estimating water in soils (LEWIS), IEEE T. Geosci. Remote, 42, 1666-1676, 2004.

Mahfouf, J.-F.: Assimilation of satellite-derived soil moisture from ASCAT in a limited-area NWP model, Q. J. Roy. Meteorol. Soc., 136, 784-798, 2010.

Mahfouf, J. F. and Noilhan, J.: Inclusion of gravitational drainage in a land surface scheme based on the force-restore method, J. Appl. Meteorol., 35, 987-992, 1996.

Mahfouf, J.-F., Bergaoui, K., Draper, C., Bouyssel, F., Taillefer, F., and Taseva, L.: A comparison of two off-line soil analysis schemes for assimilation of screen level observations, J. Geophys. Res., 114, 2156-2202, doi:10.1029/2008JD011077, 2009.

Masson, V., Le Moigne, P., Martin, E., Faroux, S., Alias, A., Alkama, R., Belamari, S., Barbu, A., Boone, A., Bouyssel, F., Brousseau, P., Brun, E., Calvet, J.-C., Carrer, D., Decharme, B., Delire, C., Donier, S., Essaouini, K., Gibelin, A.-L., Giordani, H., Habets, F., Jidane, M., Kerdraon, G., Kourzeneva, E., Lafaysse, M., Lafont, S., Lebeaupin Brossier, C., Lemonsu, A., Mahfouf, J.-F., Marguinaud, P., Mokhtari, M., Morin, S., Pigeon, G., Salgado, R., Seity, Y., Taillefer, F., Tanguy, G., Tulet, P., Vincendon, B., Vionnet, V., and Voldoire, A.: The SURFEXv7.2 land and ocean surface platform for coupled or offline simulation of earth surface variables and fluxes, Geosci. Model Dev., 6, 929-960, doi:10.5194/gmd-6-929-2013, 2013.

Medina, H., Romano, N., and Chirico, G. B.: Kalman filters for assimilating near-surface observations in the Richards equation Part 3: Retrieving states and parameters from laboratory evaporation experiments, Hydrol. Earth Syst. Sci. Discuss., 9, 1337313414, doi:10.5194/hessd-9-13373-2012, 2012.

Njoku, E., Jackson, T., Lakshmi, V., Chan, T., and Nghiem, S.: Soil moisture retrieval from AMSR-E, IEEE Trans. Geosci. Remote, 41, 215-229, 2003. 
Noilhan, J. and Mahfouf, J.: The ISBA land surface parameterisation scheme, Global Planet. Change, 13, 145-159, 1996.

Noilhan, J. and Planton, P.: A simple parameterization of land surface processes for meteorological models, Mon. Weather Rev., 117, 536-849, 1989.

Owe, M., de Jeu, R., and Walker, J.: A methodology for surface soil moisture and vegetation optical depth retrieval using the microwave polarization difference index, IEEE Trans. Geosci. Remote Sens., 39, 1643-1654, 2001.

Pellarin, T., Calvet, J.-C., and Wagner, W.: Evaluation of ERS scatterometer soil moisture products over a half-degree region in southwestern France, Geophys. Res. Lett., 33, L17401, doi:10.1029/2006GL027231, 2006.

Pipunic, R., Walker, J., Western, A., and Trudinger, C.: Assimilation of multiple data types for improved heat flux prediction: A onedimensional field study, Remote Sens. Environ., 136, 315-329, 2013.

Ragab, R.: Towards a continuous operational system to estimate the root-zone soil moisture from intermittent remotely sensed surface moisture, J. Hydrol., 173, 1-25, 1995.

Reichle, R. H.: Variational assimilation of remote sensing data for land surface hydrologic applications, Ph.D. thesis, Massachusetts Institute of Technology, Massachusetts, 2000.

Reichle, R. H. and Koster, R. D.: Bias reduction in short records of satellite soil moisture, Geophys. Res. Lett., 31, L19501, doi:10.1029/2004GL020938, 2004.

Reichle, R. H. and Koster, R. D.: Global assimilation of satellite surface soil moisture retrievals into the NASA Catchment land surface model, Geophys. Res. Lett., 32, L02404, doi:10.1029/2004GL021700, 2005.

Rüdiger, C., Calvet, J.-C., Claire, G., Holmes, T., de Jeu, R., and Wagner, W.: An intercomparison of ers-scat and amsr-e soil moisture observations with model simulations over france, J. Hydrometeorol., 10, 431-447, doi:10.1175/2008JHM997.1, 2007.
Sabater, J. M., Jarlan, L., Calvet, J.-C., Bouyssel, F., and de Rosnay, P.: rom near-surface to root-zone soil moisture using different assimilation techniques, J. Hydrometeorol., 8, 194-206, doi:10.1175/JHM571.1, 2007.

Saleh, K., Wigneron, J.-P., de Rosnay, P., Calvet, J.-C., and Kerr, Y.: Semi-empirical regressions at L-band applied to surface soil moisture retrievals over grass, Remote Sens. Environ., 101, 415426, 2006.

Saleh, K., Wigneron, J.-P., Waldteufel, P., De Rosnay, P., Schwank, M., Calvet, J.-C., and Kerr, Y.: Estimates of surface soil moisture under grass covers using L-band radiometry, Remote Sen. Environ., 109, 42-53, 2007.

Schmugge, T. J.: Remote sensing of soil moisture: Recent advances, IEEE T. Geosci. Remote, GE-21, 336-344, 1983.

Schmugge, T. J., Jackson, T. J., and McKim, H. L.: Survey of methods for soil moisture determination, Water Resour. Res., 16, 961979, doi:10.1029/WR016i006p00961, 1980.

Scipal, K., Holmes, T., de Jeu, R., Naeimi, V., and Wagner, W.: A possible solution for the problem of estimating the error structure of global soil moisture data sets, Geophys. Res. Lett., 35, L24403, doi:10.1029/2008GL035599, 2008.

Shukla, J. and Mintz, Y.: Influence of land-surface evapotranspiration on the earth's climate, Science, 215, 1498-1501, 1982.

Wagner, W., Lemoine, G., and Rott, H.: A method for estimating soil moisture from ERS scatterometer and soil data, Remote Sens. Environ., 70, 191-207, 1999.

Wagner, W., Naeimi, V., Scipal, K., de Jeu, R., and MartínezFernández, J.: Soil moisture from operational meteorological satellites, Hydrogeol. J., 15, 121-131, 2007.

Walker, J. and Houser, P.: A methodology for initializing soil moisture in a global climate model: Assimilation of near-surface soil moisture observations, J. Geophys. Res., 106, 11761-11774, 2001. 